\title{
RELEVANCIA DEL DOLO EN LA RESPONSABILIDAD EXTRACONTRACTUAL CHILENA: UNA RELECTURA DESDE EL DERECHO INGLÉS*
}

\section{CRISTIÁN BANFI DEL RÍo**}

RESUMEN: Mediante el análisis de doctrina y jurisprudencia inglesas pertinentes este artículo sostiene que es posible reinterpretar las reglas de responsabilidad extracontractual nacionales de modo de reconocer la importancia del dolo en dos contextos distintos, a saber: como una condición para atribuir la responsabilidad por el daño proveniente de ciertas actividades, en particular del ejercicio de libertades o derechos como la libertad de competir o el derecho a accionar en juicio; y como un factor que debería determinar la extensión de la responsabilidad a todos los dańos causados directamente por el delito civil, incluso los daños imprevisibles al tiempo en que aquel fue cometido, sin que la culpa concurrente de la víctima tenga el efecto de atenuar la responsabilidad del autor del hecho.

PALABRAS CLAVE: Responsabilidad; dolo; causalidad; daños; previsibilidad

\section{RELEVANCE OF INTENTION IN CHILEAN TORT LIABILITY: A REINTERPRETATION FROM ENGLISH LAW}

ABSTRACT: By analysing related English legal doctrine and case-law this article argues for the possibility of reinterpreting national tort law rules so as to recognise the importance of the intention to harm in two different contexts, namely: as a condition for attributing liability for the

\footnotetext{
* $\quad$ Este trabajo se adscribe al Proyecto Fondecyt Regular 1150976 ("Importancia del dolo en la responsabilidad civil extracontractual chilena a la luz de los sistemas francés e inglés”). Agradezco el financiamiento proporcionado por CONICYT.

Fecha de recepción: 14 de abril de 2016.

Fecha de aceptación: 29 de julio de 2016.

** Abogado; Licenciado en Derecho, Pontificia Universidad Católica de Chile; Magíster en Derecho, con mención en Derecho Privado, Universidad de Chile; LL.M. \& PhD, University of Cambridge. Profesor Asociado de Derecho Civil, Universidad de Chile (Chile). Correo electrónico: cbanfi@derecho.uchile.cl
} 
harm derived from certain activities, in particular out of the exercise of freedoms or rights such as the liberty to compete and the right to bring legal actions; and as a factor that should determine the extension of liability to all damages directly caused by the civil delict, including those which could not be foreseen at the time the tort was committed, without the victim's contributory negligence having the effect of lessening the wrongdoer's liability.

KEY WORDS: Tort liability; intention; causation; damages; foreseeability

Sumario: Preámbulo. 1) El dolo en el derecho inglés de los torts. (1.1.) Introducción. (1.2.) El dolo: requisito para atribuir responsabilidad civil en ciertas situaciones. (1.2.1.) Generalidades. (1.2.2.) Responsabilidad civil por actos de competencia desleal. (1.2.3.) Responsabilidad civil por abuso de acciones judiciales. (1.2.4.) El dolo en el fraude y en el ejercicio abusivo de funciones públicas. (1.3.) El dolo como condición alternativa a la culpa. (1.4.) La trascendencia causal del dolo. (1.4.1.) Generalidades. 2) El caso chileno. (2.1.) Introducción. (2.2.) La consideración de la gravedad de la conducta en la reparación del daño moral. (2.3.) El dolo como condición para atribuir responsabilidad civil por actos de competencia desleal y por abuso del proceso. (2.4.) La incidencia causal del dolo y por qué este debiera expandir la responsabilidad civil. (2.5.) El dolo del autor del hecho ilicito debería absorber la culpa de la víctima si ambos concurren en la producción del daño, sin proceder la compensación de culpas. Conclusiones. Bibliografía citada.

\section{Preámbulo}

Constituye poco menos que un axioma la afirmación según la cual el dolo es un concepto jurídico dogmática y prácticamente intrascendente en la responsabilidad aquiliana. En las elocuentes palabras del profesor Arturo Alessandri Rodríguez, "La distinción entre delito y cuasidelito civil es, en realidad, inútil. Carece de justificación teórica, porque ambos son hechos ilícitos. Carece también de interés práctico, porque uno y otro obligan a su autor a reparar el daño causado en idéntica forma y en su totalidad, toda vez que el monto de la indemnización se regula en atención a aquel y no a la naturaleza del hecho que lo generó. Tanto es así que nuestro Código Civil los ha sometido a una misma y única reglamen- 
tación y siempre los menciona conjuntamente (arts. 1437, 2314, 2318, 2319, 2321, 2325 y 2329)" 1 .

Esta apreciación ha ejercido considerable influencia entre nuestros académicos y jueces. La doctrina mayoritaria tiende a compartir ese aserto $^{2}$ y la jurisprudencia ha declarado constantemente que " $[\mathrm{E}] \mathrm{n}$ materia de responsabilidad cuasidelictual, la culpa no tiene grados, ni admite diferencias: hay culpa o no la hay, pues lo único que importa para los efectos del pleito, es el monto de los daños, y es esto lo que regula la indemnización, con entera prescindencia de la gravedad de la culpa" ${ }^{3}$. En consecuencia, el dolo y la culpa lata únicamente tendrían trascendencia en la responsabilidad contractual, ex art. 1558 del Código Civil ${ }^{4}$.

El presente artículo tiene por objeto cuestionar dicha aseveración. A partir de la revisión de aspectos de la doctrina y jurisprudencia anglosajona sobre ilícitos extracontractuales o torts, y de su contraste con el estado de la cuestión en la responsabilidad extracontractual en Chile, en este trabajo se sugiere y concluye que es posible reinterpretar las normas del Título XXXV del Libro IV del Código Civil en forma que se reconozca que el dolo -y la culpa lata, por su asimilación a aquel- tiene importancia en un ámbito y debería tenerla en otro.

Alessandri Rodríguez, Arturo (1943) De la responsabilidad extracontractual en el derecho civil chileno. Santiago de Chile: Imprenta Universitaria, 644 pp., p. 15.

2 Alessandri Rodríguez (1943) 28, 533 y 547; Domínguez Águila, Ramón (1990) “Consideraciones en torno a la noción de daño en la responsabilidad civil. Una visión comparatista”. Revista de Derecho Universidad de Concepción, N 188 , pp. 125-168, p. 135; DíEz Schwerter, José Luis (1997) El daño extracontractual. Jurisprudencia y doctrina. Santiago de Chile: Editorial Jurídica de Chile, 291 pp., p. 159; TApra Suárez, Orlando (2007) De la responsabilidad civil en general y de la responsabilidad delictual entre los contratantes. $3^{\mathrm{a}} \mathrm{Ed}$. Santiago de Chile: Editorial LexisNexis, 654 pp., p. 375; Barros Bourie, Enrique (2006) Tratado de responsabilidad extracontractual. Santiago: Editorial Jurídica de Chile, 1230 pp., pp. 37-38, 78 y 215-216; Domínguez Hidalgo, Carmen (2010) "El principio de reparación integral del daño y su contenido: algunas consecuencias para el derecho chileno”. En Departamento de Derecho Privado Universidad de Concepción (coordinador): Estudios de Derecho Civil V. Santiago de Chile: Editorial Abeledo Perrot - LegalPublishing, pp. 671685; Domínguez Águila, Ramón (2010) "Los límites al principio de reparación integral”. Revista Chilena de Derecho Privado, No 15, pp. 9-28, p. 27; Corral Talciani, Hernán (2013) Lecciones de responsabilidad extracontractual. 2a Ed. Santiago de Chile: Editorial LegalPublishing - Thomson Reuters, 475 pp., pp. 60 y 203-204.

3 Corte Suprema. 12 de agosto de 1953. "Silva con Arce". RDJ, T. 50, sec. 1a, p. 288; Corte Suprema. 16 de octubre de 1970. “Contra Lama, Abraham”. RDJ, T. 67, sec. 4a, p. 424; Corte Suprema. 8 de noviembre de 1971. "Contra Álvarez Hormazábal, Domingo y Álvarez, Domingo". RDJ, T. 68, sec. 4a , p. 274; Corte Suprema. "Contra Oyanedel Severino, Alfonso y Otro”. 27 de octubre de 1983. RDJ, T. 80, sec. 4a, p. 121.

4 Corte Suprema. 14 de abril de 1953. "Fueyo y Otros con Urbistondo". RDJ, t. 50, sec. 4a , p. 40; Alessandri Rodríguez (1943) 48-49 y 552; Corral Talciani, Hernán (2010) Contratos y daños por incumplimiento. Santiago de Chile: Editorial Abeledo Perrot - LegalPublishing, 328 pp., pp. 202-204; Corral Talciani (2013) 204, nota 295. 
En primer lugar, desde una perspectiva no solo normativa sino descriptiva, el dolo es y debe ser un requisito esencial para imputar el deber de reparar los daños emanados del ejercicio de la libertad de competir y del derecho a actuar en el proceso. Como se verá, los sistemas jurídicos inglés y nacional evidencian una alta coincidencia en el tratamiento de la responsabilidad por actos de competencia desleal y ejercicio abusivo de acciones judiciales.

En segundo lugar, desde un punto de vista propositivo, el dolo debiera desencadenar una responsabilidad civil más amplia que la negligencia (no grave) y la culpa concurrente de la víctima debiera ser absorbida por el dolo del autor del daño. Aun cuando no se conoce jurisprudencia chilena que admita estos efectos, se argumenta por su futuro reconocimiento.

Por de pronto, en la actualidad la jurisprudencia no ordena la indemnización de todos los perjuicios que emanan directamente de un cuasidelito sino solo de los daños previsibles por el autor al tiempo de cometer el ilícito. Esto abre la posibilidad de que, llamada a resolver litigios que versen sobre delitos civiles, la jurisprudencia extienda la responsabilidad a los perjuicios imprevisibles.

\section{1) EL DOLO EN EL DERECHO INGLÉS DE LOS TORTS}

\section{(1.1.) INTRODUCCIÓN}

En el sistema jurídico inglés existe un contraste obvio entre la responsabilidad penal y la responsabilidad civil. La primera persigue proteger el interés público mediante la imposición de un castigo al hechor en tanto la segunda tiene por objeto reivindicar los derechos e intereses de las víctimas y, esencialmente, resarcir los daños que estas sufren a raíz de las conductas ilícitas perpetradas por terceros. Asimismo, la mera posibilidad de tener que hacerse cargo de los perjuicios ocasionados a la víctima conforme a la justicia correctiva y con independencia del grado de culpabilidad con que actúe el autor del dańo, es una forma de desalentar los comportamientos nocivos 5 .

Honoré, Tony (1995) “The morality of tort Law”. En Owen, David (editor): Philosophical foundations of tort law. Oxford: Clarendon Press, 510 pp., pp. 72-95. Se ha resuelto que la responsabilidad civil debe sujetarse a la justicia correctiva y que la justicia distributiva carece de mayor incidencia en la determinación de la reparación: Thompstone v. Tameside and Glossop Acute Services NHS Trust [2008] EWCA Civ. 5, \$47. 
Con todo, la diferencia anotada no es tajante. En efecto, la responsabilidad civil también atiende fines y desempeña roles preventivos y retributivos, rasgo que se manifiesta conspicuamente en los dańos punitivos ${ }^{6}$. Por cierto, estos fines y funciones no se reducen a los daños punitivos: aquellos además se expresan en la trascendencia que el Common Law reconoce al "elemento intencional". Esta denominación comprende tanto el dolo o intención de dañar (intention) -como un fin (malicia) o como un medio para otro fin (habitualmente el propio enriquecimiento del autor del hecho) - como el desprecio o indiferencia hacia el daño que la conducta puede causar a otros (recklessness o reckless indifference), categoría equiparable al dolo eventual y a la culpa lata de los sistemas jurídicos del Derecho Civil. En efecto, en principio se reputan intentados los daños respecto de los que el autor del hecho fue indiferente. Por ejemplo, si A golpea a B intentando inferirle un daño leve y B sufre una lesión grave, A debe responder porque el dańo efectivo emana del primer golpe propinado por A, aun cuando este no haya previsto ni deseado ocasionar la herida más seria ${ }^{7}$.

Prescindiendo de las hipótesis de responsabilidad estricta, es necesario señalar que los diversos ilícitos específicos (torts) que originan responsabilidad extracontractual en Inglaterra exigen distintos grados de culpabilidad en el autor. Además, y no obstante la trascendencia del tort of negligence y el hecho de que esta figura ha desplazado a varios delitos particulares, la responsabilidad civil sigue estando estructura en torno a ilícitos y acciones específicas. Luego, no se admite un principio como el neminem laedere que dé coherencia al sistema en su conjunto ${ }^{8}$.

Asimismo, en el Common Law generalmente no interesa conocer el motivo que inspira la actuación de un sujeto: su preocupación reside en

6 Jones, Michael (2014) Clerk \& Lindsell on torts. 21 $1^{\text {st }}$ Ed. London: Sweet \& Maxwell Thomson Reuters, 2374 pp., $\$ 1-10 ;$ Kuddus v. Chief Constable of Leicestershire Constabulary [2002] 2 A.C. 122.

7 Wainwright v. Home Office [2001] EWCA Civ. 2081. Si A arroja un petardo contra un grupo de personas, una de las cuales lo lanza a otra que hace lo mismo hasta que el objeto explota en poder de la víctima, resultando lesionada, A debe responder; pues aunque solo quiso atemorizar despreció las posibles repercusiones de su acto. Además, la intervención de terceros que desvían el curso causal es un efecto previsible de la conducta de A: Scott v. Shepherd (1773) 2 W.Bl. 892.

$8 \quad$ No obstante que en Donoghue v. Stevenson [1932] A.C. 562, p. 580, Lord Atkin acuñó el "principio del vecino", del cual se desprende el deber de no dañar a terceros que previsiblemente pueden resultar perjudicados por estar vinculados directa y próximamente al autor del daño, dicho principio se limita al caso de la negligencia. Por ende, la responsabilidad civil no obedece a un canon general sino que está compuesta por una pluralidad de ilícitos particulares: Rudden, Bernard (1991) “Torticles". Tulane Civil Law Forum, Vol. 6, pp. 105-129; WeIr, Tony (2006) An introduction to tort law. $2^{\text {nd }}$ Ed. Oxford: Oxford University Press, 270 pp., p. 16. 
saber si se perpetró o no un comportamiento ilícito. Por eso, en este ordenamiento se desconoce un principio de responsabilidad por los daños causados intencionalmente; y un motivo malicioso no convierte en ilícita una conducta lícita9: "ningún uso de la propiedad que sería legitimo si obedeciera a un motivo correcto puede devenir ilicito por el hecho de ser incitado por un motivo incorrecto o incluso malicioso" 10 .

Sin embargo, al menos en tres ámbitos de la responsabilidad extracontractual el elemento intencional tiene gravitación en el derecho anglosajón.

\section{(1.2.) EL DOLO: REQUISITO PARA ATRIBUIR RESPONSABILIDAD CIVIL EN CIERTAS SITUACIONES}

\section{(1.2.1.) Generalidades}

En primer lugar, en algunos casos el dolo opera como condición para imputar la responsabilidad puesto que el ilícito en cuestión es, por definición, intencional. Esto en parte se explica por la clase de interés o derecho de la víctima que se desea cautelar, a través de la acción que nace del ilícito. Dicho interés o derecho debe ser sopesado con el que invoca el autor del daño: "debido a que la imposición de responsabilidad extracontractual en una persona vulnera de modo significativo su libertad de acción y reduce su riqueza patrimonial, el derecho, para ser justo, debe hacer un balance entre los intereses de las víctimas y los intereses de los autores del daño. Esto se hace mediante la limitación negativa de la definición de "intereses protegidos" y de "conducta sancionada", y la protección de ciertos intereses solo contra la interferencia o daño resultante de ciertos tipos de conducta sancionada..." 11 .

Luego, en determinadas situaciones la responsabilidad civil presupone un elemento intencional como mecanismo para equilibrar la seguridad de la víctima con la libertad de actuación del autor del daño, particularmente si se trata de su libertad de competir o de ejercer acciones judiciales.

\section{(1.2.2.) Responsabilidad civil por actos de competencia desleal}

Los actos de competencia desleal que generan responsabilidad civil (economic torts) requieren de algún tipo de intención.

Allen v. Flood [1898] A.C. 1, \$92, Lord Herschell.

Bradford v. Pickles [1895] A.C. 587, p. 598, Lord Halsbury.

Cane, Peter (1997) The anatomy of tort law. Oxford: Hart, 264 pp., p. 21. 
Así, el autor de la inducción al incumplimiento de contrato actúa a sabiendas y dolosamente persuade a otro a incumplir sus obligaciones en detrimento de su acreedor, rival del primero ${ }^{12}$; quien interfiere ilícitamente en un negocio ajeno emplea medios ilícitos en contra de un tercero (que podría accionar de perjuicios contra aquel) con la intención de perjudicar a un competidor que resulta dańado ${ }^{13}$; dos o más personas se coluden con la intención, predominante o no, de dañar a otra, utilizando o no medios ilícitos en su contra, quien resulta perjudicada ${ }^{14}$; una persona, con la intención principal o secundaria de perjudicar a su adversario, amenaza a un tercero con cometer un ilícito en su contra salvo que este realice un hecho o se abstenga de actuar en detrimento de ese competidor, cediendo el tercero a dicha presión ${ }^{15}$; el demandado, a sabiendas o con temeraria indiferencia de la falsedad de su declaración, y con la intención de perjudicar a su adversario, comunica mentiras sobre el negocio, bienes o servicios del competidor, ocasionándole un daño patrimonial ${ }^{16}$, y; en fin, una persona hace pasar sus productos o servicios ante los consumidores como si fueran los de su rival aprovechándose de la reputación de este $^{17}$.

Las conductas desleales a menudo producen un dańo puramente económico (pure economic loss) que corresponde al lucro cesante como la pérdida de clientela o cuota de mercado. La indemnización de este perjuicio generalmente exige la comisión de un delito civil. La mera negligencia es insuficiente, con una calificada excepción: los auditores y bancos responden de los dańos puramente patrimoniales que causan a terceros con sus asesorías, consejos o informes emitidos negligentemente ${ }^{18}$.

Pero, dejando de lado este caso puntual, la posibilidad de que se indemnice el daño puramente patrimonial exige probar el elemento intencional de cada acto de competencia desleal, para lo cual es necesario contrapesar el derecho del agente comercial afectado a que le resarzan el

$12 \quad$ Lumley v. Gye (1853) 118 E.R. 749.

$13 O B G$ v. Allan, Douglas v. Hello! \& Mainstream v. Young [2008] 1 A.C. 1, \$ 6, Lord Hoffmann, y $\$ 141$, Lord Nicholls.

14 El tort of conspiracy to injure requiere que quienes se conciertan tengan la intención predominante de dañar: Quinn v. Leathem [1901] A.C. 495; Sorrell v. Smith [1925] A.C. 700; Crofter Handwoven Harris Tweed Co Ltd v. Veitch [1942] A.C. 435. En cambio, el tort of unlawful means conspiracy exige la intención (principal o no) de dańar y el uso de medios ilícitos: Lonrho Ltd v. Shell Petroleum Co Ltd (No.2) [1982] A.C. 173; Lonrho Plc v. Al-Fayed (No.1) [1992] 1 A.C. 448; Revenue and Customs Commissioners con Total Network SL [2008] 1 A.C. 1174.

15 Rookes v. Barnard [1964] A.C. 1129.

16 Ratcliffe v. Evans [1892] 2 Q.B. 524, p. 527, Bowen L.J.

17 Reddaway v. Banham [1896] A.C. 199.

18 Hedley Byrne \& Co. Ltd. v. Heller \& Partners Ltd. [1964] A.C. 465; Caparo Industries Plc. v. Dickman [1990] 2 A.C. 605. 
daño con la libertad de competir del rival. Y es que, como acota un juez, "en una sociedad económica competitiva la conducta de una persona siempre puede tener repercusiones patrimoniales para otra $y$, en principio, la actividad económica no tiene que considerar los intereses de terceros y puede ser justificada por el hecho de que el agente persiga sus propios intereses solamente" ${ }^{19}$. El derecho de la víctima prevalecerá si el autor del daño abusó de su libertad de competir.

En consecuencia, la responsabilidad civil es un mecanismo de control de la competencia desleal de carácter limitado ya que está "diseñado solamente para hacer cumplir los estándares básicos de comportamiento civilizado en la competencia comercial" ${ }^{20}$ y "para poner freno a una conducta claramente excesiva mediante una acción por el daño económico causado intencionalmente por medios inaceptables" 21 .

\section{(1.2.3.) Responsabilidad civil por abuso de acciones judiciales}

De forma semejante, la responsabilidad civil por el ejercicio abusivo de acciones judiciales se reclama mediante el tort of malicious prosecution y el tort of abuse of civil process. En ambos casos de conculca el debido proceso al ser instrumentalizado para otro fin que el de hacer justicia. El hechor actúa con la intención de dañar a la víctima ya que no persigue reivindicar derecho alguno sino simplemente instituir un litigio frívolo a través del ejercicio de una acción desprovista de fundamento plausible, probable y razonable ${ }^{22}$. La víctima se ve forzada a defenderse incurriendo en gastos con frecuencia elevados y queda expuesta a sufrir daños patrimoniales y morales, tales como el deterioro de su salud y la afectación de su reputación ${ }^{23}$.

Para resolver estos casos el juez tiene que contrapesar el derecho del demandado a recurrir a la justicia en defensa de sus intereses o del interés público -en función de la necesidad de incentivar a los ciudadanos a colaborar con el cumplimiento de la ley- y el derecho del actor a no ser acosado con pleitos injustificados ${ }^{24}$.

Perrett v. Collins [1998] 2 Lloyd's Rep. 255, \$84, Hobhouse L.J.

$O B G$ Ltd v. Allen [2008] 1 A.C. 1, $\$ 56$, Lord Hoffmann.

OBG Ltd v. Allen [2008] 1 A.C. 1, $\$ 153$, Lord Nicholls.

Rogers, W.V. Horton (2010) Winfield and Jolowicz on tort. $18^{\text {th }}$ Ed. London: Sweet \& Maxwell, 1225 pp., $\$ \$ 20-01$ a 20-22.

23 Así, la acusación infundada y maliciosa contra un individuo por un inventado delito de pornografía infantil produjo un efecto devastador en la autoestima del actor y en sus relaciones tanto familiares como profesionales: Clifford v. Chief Constable of Hertfordshire [2011] EWHC 815. 
El tort of malicious prosecution tradicionalmente procede por la interposición de acciones penales ${ }^{25}$. Se exige malicia la que abarca tanto en el odio, rencor o venganza como un motivo deshonesto o impropio, entendiéndose por tal uno diverso de hacer justicia ${ }^{26}$. Este motivo impropio puede colegirse de la ausencia de un caso razonable y probable ${ }^{27}$, de la incredulidad del demandado respecto de los méritos de su libelo o de la falta de buena fe en la conducción del proceso, como si se procura obtener a toda costa la condena del actor o se aportan pruebas falsas o inventadas ${ }^{28}$. El ilícito queda descartado si la persecución penal está revestida de un sustento razonable aunque el agente haya actuado con malicia ${ }^{29}$.

En cambio, el tort of malicious prosecution es muy excepcional tratándose de procesos civiles y solo recientemente se ha postulado ampliarlo, por ejemplo, si se solicita la quiebra de un comerciante maliciosa e infundadamente, afectando muy negativamente su prestigio, sin que este daño quede reparado con el solo rechazo de esa demanda ${ }^{30}$. La posibilidad de que este ilícito sea aplicado a materias civiles es coherente con el hecho de que los abusos procesales son potencialmente mucho más frecuentes en este terreno ya que el volumen de litigios civiles es muy superior a la cantidad de persecuciones penales ${ }^{31}$.

Con todo, la responsabilidad civil por abuso de acciones civiles también puede alegarse mediante el tort of abuse of civil process. Este tiene lugar cuando un sujeto se vale maliciosamente de un proceso en sí fundado para un propósito ajeno al ámbito propio del mismo, como cuando procura extorsionar o presionar a la víctima ${ }^{32}$. También comete este ilícito el acreedor que demanda ejecutivamente a su deudor a sabiendas de que este ya había pagado la obligación ${ }^{33}$.

En suma, existe abuso del proceso cuando este "es meramente un pretexto para coercer de una manera completamente ajena al ámbito de la acción legal respecto de la cual la corte es llamada a juzgar" 34.

Gregory v. Portsmouth City Council [2000] 1 A.C. 419

Stevens v. Midland Counties Ry (1854) 10 Ex. 352, p. 356, Alderson.

Gibbs v. Rea [1998] A.C. 786.

Clarke v. Postan (1834) 172 E.R. 130.

Tempest v. Snowden [1952] 1 K.B. 130, p. 140, Denning L.J.

Crawford Adjusters (Cayman) Ltd. v. Sagicor General Insurance (Cayman) Ltd. [2014] A.C. 366.

31 Crawford Adjusters (Cayman) Ltd. v. Sagicor General Insurance (Cayman) Ltd. [2014] A.C. 366, $\$ 68$, Lord Wilson.

Grainger v. Hill (1838) 132 E.R. 769.

Gilding v. Eyre (1861) 142 E.R. 769; Churchill v. Siggers (1854) 118 E.R. 1389.

Crawford Adjusters (Cayman) Ltd. v. Sagicor General Insurance (Cayman) Ltd. [2014] A.C. 366, $\$ \$ 63$ y 152. 


\section{(1.2.4.) El dolo en el fraude $y$ en el ejercicio abusivo de funciones públicas}

Enseguida, cabe mencionar dos conductas que, sin reflejar el ejercicio de libertades como las aludidas, también contienen un elemento intencional.

Por un lado, el autor del delito de engaño o fraude (deceit o fraud), actuando a sabiendas, hace una falsa representación de la realidad sin creer en $-\mathrm{o}$ con temeraria indiferencia hacia- su autenticidad, con la intención de que la víctima, confiando en esa declaración, actúe en consecuencia. La representación fraudulenta conlleva la presunción simplemente legal de que el autor intentó que el destinatario confiara en ella ${ }^{35}$.

Por otro, el tort of misfeasance in public office da lugar a responsabilidad civil por abuso del derecho en el ejercicio de las funciones públicas ${ }^{36}$. El agente actúa con la intención de perjudicar a la víctima o al menos es temerariamente indiferente ante dicha eventualidad ${ }^{37}$. El elemento intencional se entiende "en un sistema jurídico basado en el imperio de la ley el poder ejecutivo o administrativo 'solo puede ser ejercido para el bien público' $y$ no para fines impropios" 38 .

Con todo, el demandado no responde si únicamente contempló la posibilidad del riesgo objetivo de dañar a la víctima: debe acreditarse que, en los hechos o subjetivamente, él fue temerariamente indiferente, actitud que se asimila a la mala fe ${ }^{39}$.

\section{(1.3.) EL DOLO COMO CONDICIÓN ALTERNATIVA A LA CULPA}

En segundo lugar, el dolo puede operar como un factor que permite atribuir responsabilidad civil en situaciones en que esta igualmente podría ser imputada sin el elemento intencional.

Así, el tort of nuisance acarrea responsabilidad civil por molestias anormales o no razonables entre vecinos. El límite de lo que se estima

35 Pasley v. Freeman (1789) 3 TR 51; Derry v. Peek (1889) LR 14 App.Cas. 337; Pan Atlantic Insurance Co Ltd v. Pine Top Insurance Co Ltd [1995] 1 A.C. 501; Barton v. County NatWest Ltd. [1999] Lloyd's rep. Banking 408.

36 Bourgoin SA v. Ministry of Agriculture [1986] Q.B. 716.

37 "[L]a indiferencia imprudente respecto de las consecuencias dañosas de la acción es tan culpable como la persecución deliberada de dichas consecuencias": Three Rivers DC v. Bank of England (No.3) [2003] 2 A.C. 1, \$ 192, Lord Steyn.

38 Three Rivers DC v. Bank of England (No.3) [2003] 2 A.C. 1, \$ 190, Lord Steyn.

39 Jones (2014) $\$ 1-59$. En cambio, en sede penal la imprudencia temeraria es evaluada objetivamente: $R$. v Caldwell [1982] A.C. 341. 
como una turbación tolerable sin dudas es excedido si un vecino actúa dolosamente.

Por ejemplo, si A -exasperado con escuchar el sonido del piano interpretado por $\mathrm{B}$ - reacciona propinando fuertes golpes con un sartén en contra del muro divisorio, esta conducta puede ser calificada como insensata dado el ánimo deliberado con que procedió su autor ${ }^{40}$.

\section{(1.4.) LA TRASCENDENCIA CAUSAL DEL DOLO}

\section{(1.4.1.) Generalidades}

En tercer lugar, el elemento intencional tiene evidente repercusión en la causalidad y, por ende, en la extensión de la indemnización de perjuicios. En principio, el demandante debe probar que el hecho ilícito del demandado le causó un daño efectivo y que este no es una consecuencia demasiado remota. Es decir, él debe acreditar que el hecho ilícito del demandado no solo fue la causa física sino también la causa normativa del daño, de suerte que ella debe atribuirse al autor ${ }^{41}$.

Conforme al but for test o condictio sine qua non el demandante debe demostrar con una probabilidad superior al 50\% (preponderancia de la prueba) que la conducta del demandado fue una condición necesaria del daño sufrido. Esta es una indagación que explica cómo se produjo el daño y que está encaminada a persuadir al juez que el demandado debe responder $^{42}$. Sin embargo, el demandado no responde de los daños demasiados alejados de su conducta ${ }^{43}$.

\section{(1.4.2.) La causalidad en la negligencia}

En el tort of negligence un daño es "demasiado remoto" si resulta imprevisible para una persona prudente enfrentada a las mismas circunstancias que el concreto demandado. En tal evento no es justo ni equitativo imputar el daño al demandado ${ }^{44}$.

Luego, aun cuando el demandado hubiese causado un daño no responderá si este no corresponde al tipo de perjuicio que habría sido previsto en circunstancias similares, o bien, si él sucedió de un modo inusual ${ }^{45}$.

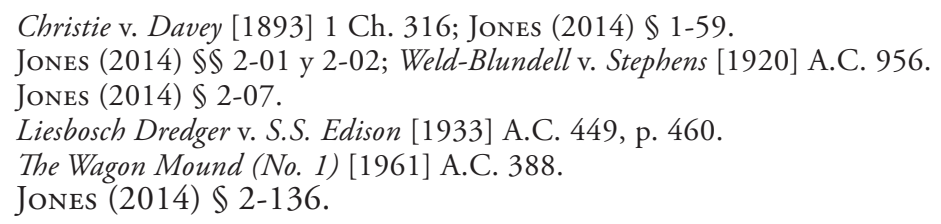


Además, puede darse la situación en que intervengan otros eventos sin los cuales el daño tampoco habría acaecido, en cuyo caso el juez deberá decidir cuál o cuáles de ellos fueron determinantes ${ }^{46}$.

Para tal efecto, es imprescindible entender el fin y el alcance de la regla que sirve de base para establecer la causa normativa del daño ${ }^{47}$ : "Una vez que se reconoce que el primer principio es que cada autor del daño debe compensar al demandante afectado respecto de esa pérdida y daño por el cual él debe ser justamente considerado responsable, las metafísicas de la causalidad puede ser guardada en su lugar apropiado: en si mismas no ofrecen en caso alguno una esperanza de solución de los problemas que abordan los tribunales en esta y otras áreas. El derecho no ha escarbado con más profundidad en los matorrales filosóficos de la causalidad que distinguir entre una causa sine qua non y una causa causans. Esta última es una tautología vacia. La primera prueba todo $y$, por tanto, nada: si A mata a $B$ a puñaladas, el nacimiento de cualquiera de ellos 30 años antes es tanto una causa sine qua non de la muerte como lo es el manejo del cuchillo. De ahi que el derecho apele a la noción de causa próxima; pero ¿cuán próxima tiene que ser? En cuanto concepto, ella no dice nada. Así, en todos estos casos la pregunta real es cuál es el daño por el cual el demandado bajo consideración debe ser tenido como responsable" 48 .

El hecho de un tercero que interviene puede constituir una causa (novus actus interveniens) que exima al demandado de responsabilidad por su conducta original ${ }^{49}$. Es el caso de la intervención dolosa del tercero: "En general aunque A incurra en culpa, él no es responsable del daño sufrido por $C$ y que B, un tercero extraño, deliberadamente eligió causar. Aun cuando A pueda haber creado la ocasión para la actividad maliciosa de B, este se convierte en una causa nueva e independiente... "50.

En otras palabras, "la cadena de causalidad es rota con más probabilidad por las intervenciones intencionales que por las negligentes, por una conducta imprudente que por una que no lo es, por actos positivos que por omisiones" 51 .

46 "Dos causas pueden ser precondiciones necesarias de un resultado particular-daño a X-aunque una puede, si los hechos justifican esa conclusión, ser tratada como la causa real, sustancial, directa o efectiva, y la otra descartada en el mejor caso como una cause sine qua non e ignorada para los efectos de la responsabilidad juridica": Stapley v. Gypsum Mines Ltd [1953] A.C. 663, p. 687, Lord Asquith.

47 Environment Agency v. Empress Car Co (Abertillery) Ltd [1999] 2 A.C. 22, \$ 31, Lord Hoffmann.

48 Rahman v. Arearose Ltd [2001] Q.B. 351, \$\$ 32-33, Laws L.J.; Jones (2014) \$ 2-93.

49 Jones (2014) \$ 2-142; Rogers (2010) \$ 6-29.

50 Weld-Blundell v. Stephens [1920] A.C. 956, p. 986, Lord Sumner.

51 Knightley v. Johns [1982] 1 W.L.R. 349, p. 365, Stephenson L.J. 


\section{(1.4.3.) La incidencia causal del dolo. La agravación de la responsabilidad}

Ahora bien, en el Common Law se considera que los comportamientos ilícitos perpetrados con la intención de dañar merecen un tratamiento diferenciado: "la gente malvada es peor que la gente descuidada y no debemos olvidarnos de esto" 52 .

En efecto, la jurisprudencia reconoce que algunas "consideraciones de politica que limitan los tipos de daños indemnizables en negligencia no se aplican igualmente a los ilícitos intencionales. Si alguien realmente intenta causar daño mediante un acto ilicito y lo consigue, generalmente no concurre razón alguna para que no deba pagar la indemnización" 53.

En este sentido, "los tribunales adoptan la no insensata perspectiva de que si el demandado infligió dolosamente un daño difícilmente puede reclamar que este devino en algo que no es lo que aquel anticipó. De ahi que la mayoría de los casos sobre el carácter remoto del daño versan sobre el tort of negligence y dicen relación con la medida en que una persona debe responder de las consecuencias que razonablemente no pudo prever" 54 . En cambio, "la intención de dañar al demandante descarta toda cuestión sobre el carácter remoto del daño" 55 .

Como se aprecia, el autor del delito civil debe responder de todos los daños directamente imputables al mismo aunque no sean razonablemente previsibles ${ }^{56}$. Precisamente una ventaja el trespass sobre el negligence estriba en que la víctima de aquel puede reclamar todos los daños directos, incluso imprevisibles 57 .

Vale decir, las consecuencias intentadas por el demandado nunca son demasiado remotas y los acontecimientos extraordinarios sobrevinientes -incluso los que el autor no pudo prever- no rompen la relación causal

\footnotetext{
ROGERS (20IO) \$4-38.

Wainwright v. Home Office [2004] 2 A.C. 406, \$\$ 44-45, Lord Hoffmann.

JONEs (2014) \$2-06.

Quinn v. Leathem [1901] A.C. 495, p. 537, Lord Lindley.

Langridge v. Levy (1873) 2 M. \& W. 519; Doyle v. Olby (Ironmongers) Ltd. [1969] 2 Q.B. 158, p. 168, Winn L.J.; Wilson v. Pringle [1987] Q.B. 237; Shelley v. Paddock [1980] Q.B. 348; Swindle v. Harrison [1997] 4 ALL E.R. 705; Smith New Court Securities Ltd. v. Scrimgeour (Asset Management) Ltd. Vickers [1997] A.C. 254, p. 284, Lord Steyn; Parabola Investments Ltd. v. Browalia Cal Ltd. [2011] Q.B. 477.

57 Wilson v. Pringle [1987] Q.B. 237; Allan v. New Mount Sinai Hospital (1980) 109 D.L.R. (3d) 634. Sin embargo, si los hechos pueden ser subsumidos indistintamente en trespass o negligence el actor no puede demandar en trespass para obtener una indemnización más generosa, debiendo el tribunal prescindir de la descripción hecha en la demanda: Letang v. Cooper [1965] 1 Q.B. 232, p. 243, Diplock L.J. Jones (2014) \$15-07.
} 
entre la conducta dolosa y los daños sufridos por la víctima"58: "No se admite a la persona fraudulenta decir que los daños no pudieron ser razonablemente previstos" 59 .

El autor doloso responde incluso por el incremento o agravación de las pérdidas del actor a consecuencia de un hecho completamente extraño y no contemplado, como el colapso repentino del mercado inmobiliario en el que la víctima invirtió incitada por el engaño realizado por el demandado ${ }^{60}$. Luego, quien perpetra un hecho intencional debe hacerse cargo de todos los daños derivados del mismo que debió anticipar. De hecho, la jurisprudencia presume la intención del autor del delito de causar los daños que él debió contemplar (imputed intention) ${ }^{61}$.

En Wilkinson v. Downton, el demandado, queriendo hacer una broma a la demandante, le dijo que el cónyuge de esta había resultado seriamente lesionado tras sufrir un accidente, provocando a la actora un shock nervioso que la afectó por varias semanas. El tribunal condenó al demandado por trespass declarando que este había cometido "deliberadamente un acto calculado para causar daño físico a la actora, esto es, para violar su derecho a la seguridad... sin que mediara justificación alguna" 62 . El juez Wright presumió el dolo de la conducta del autor, que estaba evidentemente orientada a producir un efecto de la misma especie que el daño que provocó, desestimando el argumento de la defensa de que el autor no pensó ni previó que la actora experimentaría un daño psicológico. Sin embargo, el año 2004 Lord Hoffmann corrigió esta interpretación: la intención presunta es insuficiente para configurar el trespass y condenar al demandado a indemnizar el daño emocional. La demandante debe acreditar el dolo o la imprudencia temeraria en forma subjetiva: "el demandado debe haber actuado de una manera que sabia que era injustificable e intentó causar el daño o al menos actuó sin preocuparse si lo causaría o no"63. Según indica Lord Hoffmann, el juez Wright trató de acercar la intención presunta a la negligencia para ampliar la posibilidad de resarcimiento de la víctima, ya que a la época de Wilkinson v. Downton el daño emocional solo podía reclamarse mediante una acción por trespass. En la actualidad el daño emocional también es indemnizable bajo el tort of negligence, sin

\footnotetext{
58 Hart, Herbert L.A. \& Honoré, Tony (2002) Causation in the Law. $2^{\text {nd }}$ Ed. Oxford: Oxford University Press, 516 pp., pp. 43, 77-79, 170-171 y 259.

59 Doyle v. Olby (Ironmongers) Ltd. [1969] 2 Q.B. 158, p. 167, Lord Denning M.R.

60 Slough Estates Ltd v. Welwyn-Hatfield DC [1996] 2 P.L.R. 50.

61 Jones (2014) \$2-143.

62 [1897] 2 Q.B. 57, pp. 58-59, Wright J.

63 Wainwright v. Home Office [2004] 2 A.C. 406, \$\$ 44-45.
} 
necesidad de probar un elemento intencional ${ }^{64}$, aunque solo se repara si él pudo ser previsto al tiempo del hecho ${ }^{65}$. Si la víctima elige accionar por trespass -decisión que seguramente obedecerá a su pretensión de que se le indemnicen todos los dańos directos, incluso los perjuicios imprevisibles al tiempo del hecho ${ }^{66}$, entre los cuales puede estar el daño psicológico, ella deberá probar que el dolo o la extrema indiferencia del demandado ${ }^{67}$.

La indemnización en los ilícitos dolosos comprende entonces todos los perjuicios sufridos por la víctima, tanto los daños normales -los que sufriría cualquier persona enfrentada a una situación similar a la de la víctima- como los daños consecuenciales, vale decir, los que exceden de los normales y conciernen las circunstancias especiales de la víctima ${ }^{68}$. Es lo que ocurre con el delito de fraude ${ }^{69}$.

Así, el potencial comprador de una casa engañó al mutuante como parte de un fraude hipotecario perpetrado en connivencia con el vendedor. El daño sufrido por el mutuante aumentó cuando, tras una reducción del crédito, el vendedor no le entregó el título del inmueble. El comprador fue condenado a indemnizar la totalidad de la pérdida sufrida por el actor $^{70}$.

Análogamente, la víctima de otro fraude hipotecario no solo fue indemnizada por las sumas anticipadas al demandado sino también por las siguientes partidas: los intereses que habría percibido sobre las sumas perdidas, el tiempo administrativo y de personal invertido en la investigación, la pérdida de negocios o lucro cesante y los costos derivados de préstamos adicionales incurridos debido a la pérdida de credibilidad del actor luego que el fraude fuera hecho público, el costo de mantener las reservas exigidas por el regulador, y los intereses adicionales que tuvo que ofrecer a los inversionistas ansiosos ${ }^{71}$. Solo se excluyen los dańos sufridos por la víctima a consecuencia de su falta de prudencia o sentido común ${ }^{72}$.

64 Ha devenido "innecesario diseñar un ilícito intencional o discutir qué necesaria intención -real o presunta-deberia ser": Wainwright v. Home Office [2004] 2 A.C. 406, \$ 40, Lord Hoffmann.

65 The Wagon Mound (No.1) [1961] A.C. 388.

66 Wainwright v. Home Office, [2004] 2 A.C. 406, \$ 50, Lord Hoffmann.

67 JONES (2014) \$\$ 15-14 a 15-16.

68 McGregor, Harvey (2014) McGregor on damages. 19 $9^{\text {th }}$ Ed. London: Sweet \& Maxwell -Thomson Reuters, 2146 pp., \$3-008.

69 Doyle v. Olby [1969] 2 Q.B. 158 CA, p. 167, Lord Denning M.R.; Clark v. Urquhart [1930] A.C. 28, pp. 67-68, Lord Atkin.

$70 \quad$ St Paul Travelers Insurance Co Ltd. v. Okporuah [2006] EWHC 2107.

Nationwide Building Society v. Dunlop Haywards (DHL) Ltd [2009] EWHC 254

Doyle v. Olby (Ironmongers) Ltd. [1969] 2 Q.B. 158; Banque Bruxelles Lambert SA v. Eagle Star Insurance Co Ltd [1997] A.C. 191. 
La lista puede ser aumentada con otros ejemplos: el demandado que engañó a un sujeto haciéndolo adquirir un paquete accionario que nunca le entregó fue condenado a indemnizar el capital invertido por el actor y los intereses ${ }^{73}$; el demandado que a sabiendas presentó documentación falsa al banco demandante para que este expidiera una carta de crédito fue condenado a resarcir los gastos en litigación incurridos por el actor en contra de los otros bancos involucrados en la cadena originada en ese título de crédito antes de que la falsedad fuese descubierta ${ }^{74}$; el demandado que timó al actor haciéndolo comprar un inmueble tuvo que indemnizarle hasta el impuesto de timbres y los gastos de conservación del mismo activo ${ }^{75}$; al demandante que cayó en insolvencia debido al engaño cometido por un tercero le fueron indemnizados los daños asociados ${ }^{76}$; el vendedor de un arma de fuego que declaró dolosamente que estaba en perfecto estado debió compensar los daños físicos sufridos por el comprador a raíz de la explosión del objeto ${ }^{77}$; al comprador estafado con un hogar de ancianos en estado financiero deplorable le fueron resarcidos los daños resultantes de la depresión que le produjo esa adquisición ${ }^{78}$; el demandado que a sabiendas vendió una vaca enferma tuvo que pagar al comprador el valor del ganado que este perdió al resultar contagiado por el animal adquirido ${ }^{79}$.

En definitiva, el test de causalidad es ampliamente favorable a las víctimas $^{80}$ y el autor del fraude asume el riesgo de incremento del daño sufrido por la víctima por hechos sobrevinientes aunque escapen al control del primero, como la caída del mercado que produce la pérdida de valor del inmueble objeto de la transacción ${ }^{81}$.

La postura de la jurisprudencia ante la responsabilidad por los ilícitos intencionales, como el fraude, obedece a dos motivos: "En primer lugar ella cumple un propósito disuasivo al desalentar el fraude... en la batalla en contra del fraude civil los remedios pueden jugar un rol util y beneficioso. En segundo lugar, entre el defraudador y la parte inocente, militan considera-

Archer v. Brown [1985] Q.B. 401.

KBC Bank v. Industrial Steels (UK) Ltd [2001] 1 Lloyd's Rep. 370

Butler-Creagh v. Hersham [2011] EWHC 2525.

Kinch v. Rosling [2009] EWHC 286.

Langridge v. Levy (1873) 2 M. \& W. 519

Banks v. Cox [2002] EWHC 2166.

Mullet v. Mason (1866) L.R. 1 C. \& P. 559. Jones (2014) \$\$ 2-142, 18-46 y 18-47.

Downs v. Chappell [1997] 1 W.L.R. 426; Barings Plc (In Liquidation) v. Coopers \& Lybrand (A Firm) [2002] EWHC 461, \$\$ 124-148, Evans-Lombe J.

81 Deakin, Simon, Johnston, Angus \& Markesinis, Basil (2013) Markesinis and Deakin's tort law. $7^{\text {th }}$ Ed. Oxford: Clarendon Press, 907 pp., p. 469. 
ciones morales en favor de requerir que el defraudador cargue con el riesgo de las pérdidas directamente causadas por su fraude" 82 .

\section{(1.4.4.) El dolo del autor absorbe la culpa de la víctima}

Finalmente, la culpa de la víctima no excluye ni atenúa la responsabilidad del autor del fraude ${ }^{83}$. Toda posibilidad de exención o limitación de tal responsabilidad es interpretada restrictivamente ${ }^{84}$. Por ejemplo, el autor de un engaño no puede pretender que si la víctima hubiese obrado con precaución habría evitado ser embaucada ${ }^{85}$. Análogamente, no procede reducir la indemnización que debe pagar quien conspiró para sobornar a los trabajadores del demandante a pesar de que este omitió el debido cuidado ${ }^{86}$.

Sin embargo, la víctima tiene el deber de adoptar las medidas razonables para mitigar las pérdidas ${ }^{87}$. Así, quien compra un negocio a un vendedor fraudulento debe venderlo tan pronto como sea razonablemente posible para impedir la agravación del daño. Por eso, solo se indemnizan los perjuicios que la víctima soportó hasta la fecha en que debió desprenderse del negocio ${ }^{88}$.

\section{2) El CASO CHILENO}

\section{(2.1.) INTRODUCCIÓN}

En nuestro sistema jurídico la responsabilidad civil extracontractual es, sin dudas, un instrumento esencialmente resarcitorio. Su finalidad y función fundamental consiste en restablecer a las víctimas al estado en que se hallaban antes de la perpetración de la conducta dañosa ${ }^{89}$.

\footnotetext{
82 Smith New Court Securities Ltd. v. Scrimgeour (Asset Management) Ltd. Vickers [1997] A.C. 254, pp. 279-280, Lord Steyn.

$83 \quad$ Standard Chartered Bank v. Pakistan National Shipping Corporation [2002] 3 W.L.R. 1547.

84 HIH Casualty and General Insurance Ltd. v. Chase Manhattan Bank Ltd. [2001] 2 Lloyd's Rep. 483.

85 Alliance and Leicester Building Society v. Edgestop Ltd [1993] 1 W.L.R. 1462; Nationwide Building Society v. Thimbleby \& Co [1999] P.N.L.R. 733.

86 Corporación Nacional del Cobre de Chile v. Sogemin Metal Ltd [1997] 1 W.L.R. 1396.

87 Smith New Court Securities Ltd. v. Scrimgeour (Asset Management) Ltd. Vickers [1997] A.C. 254; Jones (2014) \$3-62.

88 Downs v. Chappell [1997] 1 W.L.R. 426.

89 Corte Suprema. 26 de noviembre de 1970. "Agostinelli con Fisco". RDJ, T. 67, sec. 1a, p. 535; Corte Suprema. 6 de noviembre de 1972. "Contra Vergara Pérez, Eugenio". RDJ, T.
} 
Es más, bajo el estatuto común y general de la responsabilidad por culpa la víctima tiene derecho a la reparación integral de todos los daños padecidos, con independencia de si estos fueron causados deliberada o imprudentemente, lo que cuenta con un contundente respaldo jurisprudencial $^{90}$ y doctrinario ${ }^{91}$. La importancia del dolo y la culpa grave queda relegada a la responsabilidad contractual por aplicación del art. 1558 del Código Civil ${ }^{92}$.

\section{(2.2.) LA CONSIDERACIÓN DE LA GRAVEDAD DE LA CONDUCTA EN LA REPARACIÓN DEL DAÑO MORAL}

Sin embargo, la apreciación general sintetizada en el párrafo anterior debe ser matizada. Ante todo, la gravedad de la conducta dañosa -determinada por la intención de dañar o por la extrema negligencia- es un factor que, no pocas veces, los jueces consideran al momento de imponer una condena indemnizatoria por el daño moral93, circunstancia que da cuenta de una finalidad y una función punitiva implícita o discreta ${ }^{94}$.

69, sec. 4a, p. 181; Corte Suprema. 24 de enero de 2002. "Oviedo y Otros con Servicio de Salud de Talcahuano". GJ, N²59, p. 38.

90 CS. RDJ, T. 50 , sec. $1^{\text {a }}$, p. 288 ; CS. $R D J$, T. 67 , sec. $4^{\text {a }}$, p. 424; CS. $R D J$, T. 68, sec. $4^{\text {a }}$, p. 274; CS. RDJ, T. 80, sec. $4^{\mathrm{a}}$, p. 121.

91 Alessandri Rodríguez (1943) 28, 533 y 547; Domínguez Águila (1990) 135 y (2010) 27; Díez Schwerter (1997) 159; Tapia Suárez (2007) 375; Barros Bourie (2006) 37 38, 78 y 215-216; Domínguez Hidalgo (2010) 671-685; Corral Talciani (2013) 60 y 203-204.

92 CS. RDJ, t. 50, sec. 4a, p. 40; Alessandri Rodríguez (1943) 48-49 y 552; Corral TalCIANI (2010) 202-204 y (2013) 204, n. 295.

93 Véanse, por ejemplo, Corte Suprema. 15 de noviembre de 1927. "Wessel Duval y Cía. con Errázuriz". RDJ, T. 25, sec. 1a, p. 501; Corte Suprema. 14 de abril de 1928. "Madariaga con Ferrocarriles del Estado". RDJ, T. 26, sec. 1a , p. 141; Corte Suprema. 26 de agosto de 1941. "Porzio con Shell Mex Chile Ltda". RDJ, T. 39, sec. 1a, p. 203; Corte Suprema. 19 de abril de 1984. "Contra Celedón Silva, Jaime". RDJ, T. 81, sec. 4a, p. 29; Corte De Apelaciones de Rancagua. 18 de marzo de 1986. "Contra Báez, Juan”. RDJ, T. 83, sec. 4a, p. 36; Corte Suprema. 14 de septiembre de 1987. "Contra Gallardo Díaz, Manuel”. RDJ, T. 84, sec. 4a , p. 137; Corte de Apelaciones de Santiago. 26 de septiembre de 1990. "Curaqueo y Otros con Congregación del Santísimo Redentor". GJ, N 123, p. 47; CorTE de Apelaciones de Santiago. "Contra Montalva Navarro, Reinaldo". 4 de septiembre de 1991. RDJ, T. 88, sec. 4a, p. 138; Corte de Apelaciones de Talca. 29 de agosto de 1997. Corte Suprema. 4 de noviembre de 1997. "Contra Escobar Vera, Manuel”. RDJ, T. 94, sec. 4a, p. 258; Corte Suprema. 2 de diciembre de 1998. "Contra Berenguela Orellana, Javier". FM, No 481, p. 2737; Corte Suprema. 19 de mayo de 1999. "Contra Monroy Izquierdo, Mario". FM, $\mathrm{N}^{\circ}$ 486, p. 730; Corte de Apelaciones de Santiago. 1 de septiembre de 2003. "Soto con Banco Santander". GJ, No 279, p. 115; Corte Suprema. 7 de agosto de 2008. Rol N 935-2008. "Contra Fuenzalida Durán, Felipe"; Corte Suprema. 3 de diciembre de 2015. Rol N²9.365-2014. "Vásquez y Otros con Hospital Carlos Van Buren".

94 Alessandri Rodríguez (1943) 30-31 y 546; Domínguez Águila (1990) 133; Aedo BaRRENA, Cristian (2001) El daño moral en la responsabilidad contractual y extracontractual. 


\section{(2.3.) EL DOLO COMO CONDICIÓN PARA ATRIBUIR RESPONSABILIDAD CIVIL POR ACTOS DE COMPETENCIA DESLEAL Y POR ABUSO DEL PROCESO}

En segundo lugar, paulatinamente la jurisprudencia patria ha ido reconociendo que no es posible imputar responsabilidad civil por los daños derivados del ejercicio de algunos derechos subjetivos o libertades sin la demostración de que estos han sido objeto de abuso, erigiéndose el dolo en la expresión del abuso del derecho o libertad correspondiente.

Esta particularidad es evidente en los primeros litigios sobre responsabilidad civil resueltos por nuestros Tribunales Superiores de Justicia, tanto por los actos de competencia desleal como por el ejercicio abusivo de acciones judiciales. En ambos ámbitos los daños son generalmente un efecto colateral del ejercicio de las libertades de competir y de accionar judicialmente. En efecto, estas libertades operan como causales de justificación que excluyen la responsabilidad civil, a menos que su titular cometa un delito civil, o un cuasidelito con culpa grave, ya que tal conducta configura un abuso del derecho.

Así, en materia de competencia desleal, la todavía incipiente jurisprudencia reconoce, entre otros y a título enunciativo, que "la participación de un agente de mercado -extraño al contrato, pero inmerso en la misma actividad que alguno de los contratantes-, en las circunstancias que contribuyen, propenden o configuran el incumplimiento contractual de un cliente o de un usuario en desmedro de un competidor, se encuentra dotada de igual connotación de ilicitud, y, en todo caso, debe estimarse contraria a la buena fe o a las buenas costumbres mercantiles. En la especie, lo afirmado es particularmente manifiesto, pues el resultado inevitable de dichos actos de competencia, ejercidos por medios ilegitimos, se traduce invariablemente en el resultado lesivo que identifica a esta clase de ilicitos, a saber, el efecto de desviar la clientela de un agente de mercado a otro, lo que, en el caso de marras, se traduce en que el combustible que los concesionarios debian comprar o recibir de Copec S.A., para, a su vez, venderlo al público, es, finalmente, comprado a la demandada"95; "que la relación entre [el socio que se retiró] con la demandada da cuenta, sin duda alguna, de una conducta que se sub-

Santiago de Chile: Editorial Libromar, 517 pp., pp. 317-349; Díez Schwerter (1997) 163; Barros Bourie (2006) 166-167, 218-219 y 308-309; Domínguez Hidalgo, Carmen (2006): "Algunas consideraciones en torno a la función de la responsabilidad civil en Chile". En Varas Braun, Juan Andrés y Turner Saelzer, Susan (coordinadores): Estudios de Derecho Civil. Santiago de Chile: Editorial LexisNexis, pp. 585-605; Corral Talciani (2013) 64. 
sume plenamente en el artículo 3 de la Ley No 20.169, ya que teniendo este la calidad de representante legal de la demandante figura con poder ante el Banco... para realizar operaciones a favor de la demandada, facultad de la que por cierto se deduce que la demandada ha obrado en forma concertada y con conocimiento de los hechos"96; "que en este mismo orden de ideas... en materia civil, la buena fe se presume y si bien es cierto los contratos deben ejecutarse de buena fe y en esto, sus participes no solamente estarán a lo que alli se expresa sino que a lo que emana de la naturaleza de la obligación, este principio debe entenderse relacionado necesariamente con lo que constituye a contrario sensu la mala fe; la que no obstante no encontrarse definida en nuestro Código Civil se puede entender por ella en materia de derecho, como la actitud fraudulenta o de engaño por parte de quien conviene un acuerdo, con ánimo de perjudicar a la otra parte contratante, esto es conocido en materia penal, como el dolo; situación respecto a la cual esta sentenciadora no ha adquirido la convicción a la luz de los antecedentes tenidos a la vista, ya que si bien es cierto se produjo un efecto indemnizatorio respecto a Prolam más que significativo, al producirse el desvío de clientela, que ha resultado evidente, de las declaraciones tanto de la demandante como de la demandada, ya que el propio testigo de la actora, que depone sobre la materia, lo reconoce y señala que lo que sabe es por lo que algunos clientes que no se fueron de Prolam le han contado, lo que resulta evidentemente ser catalogado como un testimonio de oidas; de esta manera no ha quedado acreditado fehacientemente en esta sede jurisdiccional la intención dolosa que requiera la norma transcrita para configurar la causal genérica de competencia desleal'97. En suma, los actos de competencia desleal son calificados por la jurisprudencia chilena como comportamientos dolosos, esto es, "un acto deliberado, conducente a desviar clientela y, por esto, revestido

2009, y por Corte Suprema. 12 de noviembre de 2010. Rol № 3.655-2010. "Compañía de Petróleos de Chile Copec S.A. con Capdevilla Transportes Limitada".

20 Juzgado Civil de Santiago. 27 de noviembre de 2008. Rol No 11.535-2008, cons. $15^{\circ}$. Corte de Apelaciones de Santiago. 13 de enero de 2010. Rol No 868-2009. Corte Suprema. 17 de agosto de 2012. Rol N².428-2010. "Sociedad Imperial Travel \& Reps. Ltda. con Sociedad Imperial Tours Ltda".

97 8o Juzgado Civil de Santiago. 12 de julio de 2012. Rol No 15.139-2011, cons. 28 $8^{\circ}$. Corte de Apelaciones de Santiago. 1 de abril de 2014. Rol No 6.335-2012. Corte SupreMA. 31 de julio de 2014. Rol N 11.531-2014. "Prolam con Sánchez". La Corte Suprema, ratificando lo resuelto en ambas instancias y rechazando el recurso de casación en el fondo deducido por la actora, añadió: "Tercero: Que, en lo que atañe a la impugnación, la sentencia cuestionada dejó establecido, que aun cuando algunos de los hechos acreditados imputados a los demandados pudieran ser estimativos como contrarios a los compromisos contractuales contraídos con la demandante, ello no resulta suficiente dado el alto grado de subjetividad, ya que no lograron acreditarse en términos tales que produjeran la convicción necesaria para una condena". 
del carácter de mala fe o dolo"98. Otros pronunciamientos judiciales, quizá incluso más evidentes, no se encuentran firmes ${ }^{99}$.

Análogamente, la jurisprudencia supedita la responsabilidad civil por daños derivados del ejercicio de acciones judiciales a la demostración de un comportamiento abusivo, frecuentemente intencional. Por ejemplo, se ha resuelto que la sola circunstancia que una empresa interponga las acciones judiciales pertinentes para defender su posición dominante en el mercado relevante "por si solas no constituyen un atentado a la libre competencia, salvo que ellas concurrieran conjuntamente con conductas de abuso del derecho" y "tampoco constituye una conducta atentatoria contra la libre competencia el hecho de que [IANSA] hubiese pretendido incorporar las mezclas de azúcar o preparaciones alimenticias a la banda de precios del azúcar, pues ello no pasa de constituir el legitimo ejercicio del derecho de petición consagrado en la Constitución Politica de la República"100; que "lo importante es determinar si el agente del supuesto daño al ejercer la acción o al hacer la petición jurídica abusa del derecho. Es decir, si como titular del mismo, se ha colocado fuera del marco legal a objeto de obtener un beneficio propio. Es esta la hipótesis o presupuesto fáctico que haria responder de los perjuicios que una acción de esta naturaleza pueda provocar, tal conducta generaría responsabilidad pues configura un delito civil, el que por cierto debe ser acreditado en la causa aplicando para ello las normas de responsabilidad extracontractual" y "no existe prueba idónea para concluir que los representantes de la demandada al ejercer sus derechos en las causas anotadas, hayan excedido el interés legitimo tutelado, actuado de mala fe en perjuicio

98 Corte de Apelaciones de Concepción. 16 de abril de 2015. Rol No 547-2014, cons. $6^{\circ}$. "Maquival Chile Limitada con Eserma S.A".

99 V. gr., "... es necesario que concurra dolo, al menos eventual. En efecto, el artículo $3^{\circ}$ de esa Ley exige que la conducta sea contraria a la buena fe o a las buenas costumbres. Lo contrario u opuesto a las buena fe es la mala fe y la mala fe es el dolo. El entendido anterior es, además, el más razonable considerando que competir es lícito y la consecuencia de la competencia entre los oferentes, que es arrebatarse clientela, también lo es. En este sentido esta sentenciadora comparte en términos generales la doctrina del autor don Cristián Banfi (Responsabilidad civil por competencia desleal. Estudio de derecho chileno y comparado, Thomson Reuters, Santiago, Chile, 2013, por ejemplo pp. 12-13)", I ${ }^{\circ}$ Juzgado Civil de Santiago. 26 de mayo de 2015, Rol No 5.096-2012, cons. 58 . "Danone con Soprole"; “... las demandadas... planificaron los actos que configuraron competencia desleal... que tuvieron como consecuencia, la desviación de clientela y la desorganización interna de la compañia", verificándose "el elemento subjetivo que configura el sistema de atribución de responsabilidad extracontractual, en este caso, la actuación que configura las infracciones establecidas en los articulos $3^{\circ}$ y $4^{\circ}$ letra $f$ ) de la Ley sobre competencia desleal, y en consecuencia, configuran una actuación a lo menos culpable de las demandadas, en virtud de los innumerables antecedentes probatorios que se acompañaron al proceso", $22^{\circ} \mathrm{JUZGA}-$ do Civil de Santiago. 9 de julio de 2014. Rol No 21.950-2012, cons. $49^{\circ}$ y $74^{\circ}$. "WAC Research S.A. con Octogone Chile S.A y Octogone Gestión S.A”.

100 V. gr., Corte Suprema. 30 de noviembre de 2005. Rol N 4.762-2005, cons. $7^{\circ}$ y $9^{\circ}$. "Asociación Gremial de Industrias Proveedoras, Agip A.G”. 
de la actora o incurrido en un error inexcusable al relatar los hechos en sus acciones o defensas. Desde otra perspectiva, y aun estimando que el abuso del derecho no es más que un ilicito civil que debe analizarse en conformidad a las reglas generales de culpa o dolo, tampoco se advierte la intención de dañar o la falta de diligencia, cuidado o debida atención en el ejercicio del derecho que se reclama"101; que "si se entiende esta institución [abuso del derecho] como el exceso o desviación del interés jurídicamente protegido por el derecho positivo, no puede concluirse que el... deducir una demanda en contra de... ante un tribunal incompetente, importe apartarse del interés tutelado por la norma jurídica o, dicho de otro modo, teniendo el demandado... a accionar contra esta persona jurídica, al ejercer dichas prerrogativas no consta que se haya excedido o desviado del interés juridicamente protegido por esos derechos... Nadie podrá negar que el señor.. efectivamente ejerció derechos que le pertenecian, como el de... demandar a la actora ante el... Juzgado Civil de esta ciudad, actos todos que se encuentran dentro del interés de su derecho subjetivo, no lo exorbitan, no lo desvian. Es decir, la conducta desplegada por el demandado... no es extraña al interés juridicamente protegido por los derechos que se ejercieron"102; "el hecho de demandar [Industrias Princesa] a las empresas antes indicadas, por estimar que a estas les corresponde responsabilidad extracontractual por haber construido sobre parte del terreno que alega de su dominio el camino y luego explotarlo, constituye unicamente el ejercicio de un derecho, como es la interposición de la acción para obtener los perjuicios que considera procedentes, sin que pueda estimarse con ello que ha existido el abuso que se demanda, aun de desecharse finalmente por el Tribunal, pues de lo contrario, cada vez que un demandante pierda la acción intentada, podría entenderse que a su respecto existió tal abuso" 103 ; que "... no es posible determinar que haya existido un ejercicio abusivo de actuaciones administrativas, puesto que no se comprobó que el demandado hubiese obrado maliciosa o temerariamente o de mala fe. Por el contrario, los antecedentes previamente consignados muestran que tanto la oposición como el recurso de reclamación tenian una base fáctica y juridica, de las que razonablemente era posible deducir que, quien las ejerció, buscaba hacer valer sus derechos... En consecuencia, analizados los antecedentes conforme a las reglas de la sana critica, no puede establecerse que las actuaciones administrativas

101 Corte de Apelaciones de Santiago. 1 de septiembre de 2009. Rol No 4.318-2008, cons. $2^{\circ}$ y $5^{\circ}$. "Silva con Soc. Sade Chile Ltda".

102 Corte de Apelaciones de Santiago. 2 de septiembre de 2010. Rol No 3.377-2008, cons. $17^{\circ}$. "Sociedad Nacional de Procesamiento de Datos S.A. con Sone Cisternas y Transporte Inteligente Multimodal Chile S.A”.

103 Corte Suprema. 15 de enero de 2013. Rol N 9.336-2010, cons. 14. "Industrias Princesa Limitada con Fisco de Chile". 
intentadas por Roche hayan tenido por finalidad impedir, restringir o entorpecer, la entrada de Recalcine al mercado de los medicamentos... "104.

En definitiva, es posible advertir un notable parecido entre los economic torts, el tort of malicious prosecution y el tort of abuse of civil process, de un lado, y el régimen de responsabilidad extracontractual chileno por competencia desleal y abuso del proceso, de otro lado.

\section{(2.4.) LA INCIDENCIA CAUSAL DEL DOLO Y POR QUÉ ESTE DEBIERA EXPANDIR LA RESPONSABILIDAD CIVIL}

En tercer lugar, una doctrina minoritaria argumenta que el dolo debería tener una incidencia en la determinación del nexo causal entre el hecho y el daño y, por tanto, que debería influir en la extensión de la responsabilidad extracontractual. Quien comete un delito civil, o un cuasidelito con extremo descuido, debería hacerse cargo de todos los perjuicios que emanan directamente de su comportamiento, aun cuando ellos excedan del curso ordinario de los acontecimientos ${ }^{105}$. El autor de un delito civil debería ser obligado a resarcir a la víctima todos los daños que su hecho ha infligido a la víctima: no solo los perjuicios que el buen padre de familia, colocado en las mismas circunstancias que el autor, habría podido prever, sino también los daños imprevisibles a la época de cometer la conducta ${ }^{106}$.

No se trata que los jueces impongan daños punitivos ${ }^{107}$ sino que discriminen entre hechos intencionales (o gravemente negligentes) y hechos

104 Corte Suprema. 23 de julio de 2013. Rol No 8.243-2012, cons. 21 ${ }^{\circ}$. "Laboratorios Recalcine S.A. con Roche Chile Ltda”.

105 Barros Bourie (2006) 404-405 y 989 (indica, respectivamente, que "[S]i el agente ha actuado con dolo o culpa grave" y agrega que "las razones que justifican limitar la responsabilidad por culpa al desarrollo normal de los acontecimientos, no rigen respecto del hecho doloso, porque resulta justo que quien actúa con completa desaprensión de los intereses de los demás asuma incluso las consecuencias extraordinarias de su acción. Por el contrario, ninguna responsabilidad podrá ser atribuida, incluso a quien haya actuado con dolo, si el resultado dañoso es independiente del riesgo creado por su acción", y que "[E]s un principio jurídico general que quien actúa con dolo asume las consecuencias de su conducta de una manera más extensa que si ha obrado con mera negligencia, de modo que al momento de definir los perjuicios objetivamente atribuibles al hecho del ofensor debe entenderse que el dolo hace que la responsabilidad se extienda incluso a los perjuicios extraordinarios, que están excluidos de la reparación si el ilícito es meramente culpable").

106 BANFi DEL Río, Cristián (2012) "Por una reparación integral del daño extracontractual limitada a los hechos dolosos o gravemente negligentes". Revista Ius et Praxis, Año 18, № 2, pp. 3-32.

107 Por cierto, ello generaría problemas de constitucionalidad. Véase, v. gr., Segura Riveiro, Francisco (2005) "Algunas consideraciones sobre la pena privada y los daños punitivos en el derecho civil chileno". En Varas Braun, Juan Andrés y Turner Saelzer, Susan (coordinadores): Estudios de Derecho Civil. Santiago de Chile: Editorial LexisNexis, pp. 635-655; BA- 
imprudentes para los efectos de establecer la relación causal y el alcance de la indemnización de perjuicios. El autor de un hecho ejecutado con intención de dañar, con total indiferencia o con suma negligencia, debería asumir todos los daños que emanan directamente de su conducta sin beneficiarse con la regla de previsibilidad, la que debería reservarse para hechos meramente culpables ${ }^{108}$.

No conocemos jurisprudencia nacional que extienda la responsabilidad civil por delito a todos los daños directos. Sin embargo, sí existen fallos que han declarado que la regla de la previsibilidad es inherente a la negligencia ${ }^{109}$ y que el autor del cuasidelito solo debe indemnizar los perjuicios directos previsibles al tiempo de perpetrar ese hecho ${ }^{110}$. Así, en uno de los fallos más recientes, la Corte Suprema señaló “... que la previsibilidad debe considerarse como requisito constitutivo de la culpa, pues permite distinguir la acción culpable del caso fortuito... la previsibilidad... no hace referencia a un fenómeno psicológico, sino a aquello que debió ser previsto, atendidas las circunstancias... Asi, se ha fallado que "no hay culpa cuando el hecho no pudo razonablemente ser previsto".. (Barros Bourie, ob. cit. pág. 90)... En este sentido, el autor Cristián Banfi del Rio (en Revista Ius et Praxis, Año 18, $N^{\circ}$ 2, 2012, pp. 3-32), nos ilustra que "la previsibilidad está presente en dos aspectos estructurales de la responsabilidad extracontractual. En primer lugar, la previsibilidad es inherente a la culpa. Esta consiste en no prever lo que una persona razonable habría podido prever... Por eso, de igual modo como el deudor debe responder de los daños previsibles a la época de contratar, el autor del cuasidelito debe hacerse cargo exclusivamen-

rros Bourie (2006) 304-309; Larraín PÁEz, Cristián (2009) "Aproximación a los punitive damages". En Pizarro Wilson, Carlos (coordinador): Estudios de Derecho Civil IV. Santiago de Chile: Editorial LegalPublishing, pp. 707-719.

BANFi del Río (2012) 3-32 y BANFi Del Río, Cristián (2013) Responsabilidad civil por competencia desleal. Estudio de derecho chileno y comparado. Santiago de Chile: Editorial LegalPublishing - Thomson Reuters, 382 pp.

109 V. gr., Corte Suprema. 23 de septiembre de 1947. "Perkes y Otra con Garibaldi". RDJ, T. 45, sec. $1^{\text {a }}$, p. 216; Corte de Apelaciones de Santiago. 3 de octubre de 1958. Corte Suprema. 12 de mayo de 1959. "Friedl con Empresa de Transportes Colectivos del Estado". RDJ, T. 56, sec. 1a , p. 133; Corte Suprema. 15 de septiembre de 1964. "Contra Maguire Seguel, John". RDJ, T. 61, sec. 4a, p. 372; Corte Suprema. 24 de marzo de 1965. "Contra Asjra Bondo, Alberto". RDJ, T. 62, sec. 4a , p. 31; Corte Suprema. 17 de octubre de 1972. "Contra Rivas Moreno, Jorge". RDJ, T. 69, sec. 4a, p. 168; Corte Suprema. 12 de agosto de 1981. "Contra Martínez González, Miguel”. RDJ, T. 78, sec. 4ª p. 120.

110 V. gr., Corte Suprema. 24 de septiembre de 1943. "Jaramillo con Alfonso y Otros". RDJ, T. 41, sec. 1a, p. 228; Corte de Apelaciones de Santiago. 27 de diciembre de 1996. "Miranda y Otra con Banco de Santiago". GJ, N 198, p. 55; Corte Suprema. 24 de marzo de 2004. "Perrot con Banco del Estado de Chile". GJ, N 285, p. 138; Corte Suprema. 12 de junio de 2015. "Holzmann con Agrícola Las Colinas de Tapihue Limitada". Rol N ${ }^{\circ}$ 26.201-2014. 
te de los daños que eran previsibles al tiempo de ejecutar el hecho. En este sentido, y contra la opinión clásica (Alessandri, De la Responsabilidad, cit. nota n. 4, p. 552), el art. 1558 del Código Civil no es en absoluto ajeno a la responsabilidad extracontractual (asi se aprecia en Barros, Tratado, cit. nota n. 5, pp. 91 92). Esta norma y el art. 44 del mismo Código llevan lógicamente a concluir que la previsibilidad es consustancial a la culpa. Así, quien infringe un contrato culpablemente o perpetra un cuasidelito solo responde de los daños que los contratantes pudieron prever al celebrar el contrato o que un sujeto prudente habria podido contemplar a la época de ejecutar el hecho nocivo. En segundo lugar, la previsibilidad es un criterio jurídico que, aplicado particularmente a la causalidad adecuada, ayuda a atemperar los efectos de la condictio sine qua non, de manera de imputar al autor los daños que son no solo consecuencia necesaria sino también directa de su hecho. Por consiguiente, el autor del ilicito no responderá de los daños imprevisibles porque no pudo anticiparlos ni controlarlos, esto es, escaparon al curso normal de los acontecimientos..." 111 .

Esta jurisprudencia es relevante por dos razones. Primero, porque al establecer que la responsabilidad por cuasidelito comprende únicamente los daños directos previsibles a la fecha del ilícito, se desmiente la afirmación clásica de que en el ámbito extracontractual la distinción entre culpa y dolo es intrascendente pues la víctima tiene derecho a la reparación integral y el criterio decisivo es el daño sufrido al margen de la forma en que este haya sido causado ${ }^{112}$. De acuerdo a la jurisprudencia en comento tal aserto merece ser calificado: la víctima tiene derecho a que le sean reparados todos los dańos derivados directamente del cuasidelito siempre que ellos hayan sido previsibles bajo el estándar de diligencia exigible. Esto implica admitir que la lógica del art. 1558 del Código Civil no es ajena a la responsabilidad extracontractual sino solo que aquella debe ser referida al momento en que se realiza la conducta dańosa ${ }^{113}$.

Segundo, si la víctima de un cuasidelito tiene derecho a la reparación de todos los daños directos previsibles a la fecha de su ejecución, no sería absurdo ni injusto que en el futuro la jurisprudencia declarara que - a contrario sensu- la indemnización por el delito civil debería abarcar todos los daños directos, incluso los imprevisibles al momento de la perpetración

111 CS. Rol N² 26.201-2014, cons. $4^{\circ}$.

112 Alessandri Rodríguez (1943) 15

113 Barros Bourie (2006) 91-92; BANFi del Río (2012) 3-32, v. gr., 6 ("[A] sí como la infracción culpable de una obligación da lugar al resarcimiento de los daños directos previsibles al tiempo del contrato, asi también la responsabilidad por el cuasidelito civil realizado con negligencia leve o levísima debiera reducirse a los daños directos previsibles a la época de la ejecución del hecho"). 
del comportamiento doloso o gravemente negligente. Esto no significaría, reiteramos, una imposición de daños punitivos porque la responsabilidad quedaría siempre circunscrita a los daños causalmente vinculados con el hecho generador de los mismos, con la sola particularidad de que el autor no podría pretender que su deber de indemnizar a la víctima se restringe a los daños que una persona prudente habría podido prever en las mismas circunstancias sino que deberá igualmente hacerse cargo de los daños que exceden ese marco de previsibilidad.

Un argumento de texto que podría reforzar esta idea es el art. 1458 inc. $2^{\circ}$ del Código Civil, al conferir la acción indemnizatoria contra el o los terceros que han fraguado el dolo "por el total valor de los perjuicios", regla que demuestra que el dolo es uno y el mismo y que el Código Civil siempre es tratado como un delito civil ${ }^{114}$. Por cierto, de contrario puede esgrimirse que el art. 2329 inc. $1^{\circ}$ del Código Civil ordena reparar todo daño que pueda imputarse indistintamente a malicia o negligencia de otra persona. Sin embargo, la cuestión precisamente consiste en distinguir el daño imputable causalmente a la culpa de aquel atribuible al dolo: solo en el primer caso la responsabilidad está limitada a las consecuencias normales y previsibles por el estándar de conducta aplicable en la especie.

En cambio, el criterio de previsibilidad es ajeno a quien actúa con intención de dañar o con total indiferencia a la posibilidad de que su conducta pueda lesionar a otros: "El autor del delito... se obliga, muy a su pesar y por el solo efecto de la ley, a reparar las consecuencias de su acto: su voluntad es indiferente. Importa poco que se hayan previsto o no los daños causados a la víctima" 115 .

En el caso de dolo -o de la culpa grave- la causalidad debería ser más extensa que si se trata de mera negligencia, pues la previsibilidad es un criterio de imputación objetiva propio de los cuasidelitos civiles. En este sentido, la consideración del sistema anglosajón puede arrojar luces acerca de la manera de releer nuestro propio estatuto de responsabilidad extracontractual por la vía de reconocer la importancia causal específica de los comportamientos dolosos o que revelan absoluta desaprensión en su agente.

En definitiva, el delito no solo es más ominoso que el cuasidelito sino que la repercusión causal de aquel generalmente es más intensa y determinante que la de este. En efecto, la probabilidad de infligir un daño aumenta en la misma medida que el agente tiene el propósito deliberado

\footnotetext{
114 Chadwick Valdés, Tomás (1939) “De la naturaleza jurídica del dolo civil”. Revista de Derecho y Jurisprudencia, T. 36, I, pp. 5-105, pp. 18-20 y 63.

115 Chadwick Valdés (1939) 91.
} 
de producir dicha consecuencia (o, al menos, es indolente ante tal contingencia) que cuando simplemente omite adoptar el grado de cuidado exigible. El delito implica la intención de dańar como un fin o como un medio para otro fin y la conducta gravemente descuidada entraña una absoluta desconsideración hacia los demás. En ambos casos el autor asume un mayor riesgo de lesionar a otro. Como enseña un jurista español, "el dolo supone la asunción por el sujeto de la máxima probabilidad del resultado, en cuanto que es deseado por él. En la culpa lataldolo eventual, el autor no desea el daño, pero asume que existe una elevada probabilidad de que se produzca. En la culpa levisima, la previsibilidad del resultado es prácticamente inexistente y totalmente nula en el comportamiento diligente. Por esto, el juicio de previsibilidad no solo determina la imputabilidad subjetiva, sino también la cuantía del daño resarcible. Esto es asi tanto en la responsabilidad contractual como extracontractual, pues aqui debe entrar en juego el criterio de intolerabilidad que sirve para justificar una mayor extensión de la deuda indemnizatoria en relación con el daño causalmente imputable a la conducta $o$ actividad del agente" 116 . En otras palabras, el autor de dolo "persigue que el daño se produzca o, al menos, asume voluntariamente su causación como consecuencia necesaria o probable de su conducta"117. Podrá disputarse si una concreta conducta dolosa o gravemente negligente es más o menos riesgosa que una meramente culpable ${ }^{118}$, pero en principio es lógico afirmar que es más probable que acaezca el daño cuando este ha sido intentado que cuando únicamente ha sido previsto ${ }^{119}$. Desde una perspectiva filosófica se tiende a aceptar que es más probable que acaezca un resultado que ha sido intentado por el agente que uno que únicamente ha sido contemplado por aquel ${ }^{120}$. Desde el enfoque de análisis económico del derecho se esgrime que entre el acto intencional y la probabilidad de dañar a otros existe un nexo directamente proporcional. Esto permite colegir la intención de dañar de la peligrosidad de la actividad, junto con la entidad

116 Reglero Campos, Fernando (2014) “Los sistemas de responsabilidad civil”. En Reglero Campos, Fernando y Busto Lago, José Manuel (coordinadores): Tratado de responsabilidad civil. 5a Ed. Cizur Menor: Editorial Thomson Reuters, T. I, 1896 pp., cap. 2, pp. 265-315, p. 304.

117 Peña López, Fernando (2011) Dogma y realidad del derecho de daños: imputación objetiva, causalidad y culpa en el sistema español y en los PETL. Cizur Menor: Editorial Thomson Reuters, 159 pp., p. 87.

118 Domínguez Ấguila, Ramón (2001) "Aspectos de la relación de causalidad en la responsabilidad civil con especial referencia al derecho chileno". Revista de Derecho Universidad de Concepción, No 209, pp. 7-27, pp. 24-25.

119 Banfi Del Río (2012) 22.

120 Kenny, Anthony (1966) "Intention and purpose". Journal of Philosophy, No 63, pp. $642-$ 651, p. 650 . 
del daño y el costo de evitarlo ${ }^{121}$. Los actos culpables, por el contrario, suscitan riesgos cuya probabilidad de ocurrencia es notoriamente menor que las conductas dolosas ${ }^{122}$. En definitiva, "es más probable que una conducta más culpable sea identificada como la causa de un resultado que una conducta menos culpable"123.

\section{(2.5.) EL DOLO DEL AUTOR DEL HECHO ILÍCITO DEBERÍA ABSORBER LA CULPA DE LA VÍCTIMA SI AMBOS CONCURREN EN LA PRODUCCIÓN DEL DAÑO, SIN PROCEDER LA COMPENSACIÓN DE CULPAS}

El problema acerca de si la culpa de la víctima que concurre a la materialización del daño (descartando el caso en que ella es causa exclusiva del daño) reduce la responsabilidad del autor del delito civil puede zanjarse atendiendo a la gravedad de los comportamientos de uno y otra parte, a la incidencia causal de cada conducta con independencia del dolo o culpa con que hayan sido perpetradas ${ }^{124}$ o bien considerando ambas circunstancias $^{125}$.

Si la cuestión es examinada desde un ángulo estrictamente causal habría que concluir que, una vez probado que el daño sufrido por la víctima en parte se originó en la negligencia de esta y en parte en el hecho doloso del demandado, la responsabilidad del segundo debería ser atenuada por el juez, incluso de oficio, dados los términos imperativos del art. 2330 del Código Civil ${ }^{126}$. Parte de la jurisprudencia más reciente respalda esta

\footnotetext{
121 Landes, William \& Posner, Richard (1987) The economic structure of tort law. Cambridge, MA: Harvard University Press, 329 pp., pp. 151-152, 158-159 y 167-168.

122 Wright, Richard (1985) "Causation in tort law". California Law Review, Vol. 73, pp. 1737-1828, p. 1770 .

123 Cane, Peter (2001) "Responsibility and fault: a relational and functional approach to responsibility”. En Cane, Peter \& Gardner, John: Relating to Responsibility. Essays for Tony Honoré on his Eightieth Birthday. Oxford: Hart, 246 pp., p. 107.

124 “... si el daño tiene por causa la culpa de ambas partes, ambas deben soportarlo en la proporción en que han contribuido a producirlo... Es indiferente que las culpas del agente y de la víctima sean de igual o distinta gravedad... La ley no distingue... ": Alessandri Rodríguez (1943) 574.

125 BARros Bourie (2006) 435-436. Una clara e interesante descripción de las tres alternativas referidas, inclinándose por el criterio causal, en: BAHAmondes Oyarzún, Claudia y PizaRro Wilson, Carlos (2012) "La exposición de la víctima al daño: desde la culpabilidad a la causalidad". Revista de Derecho de la Pontificia Universidad Católica de Valparaiso, Vol. 39, pp. 39-52. Otro acucioso estudio del tópico, con un sugerente análisis normativo de la culpa de la víctima, en: Aedo Barrena, Cristian (2013) "El tratamiento dogmático de la culpa de la víctima en la responsabilidad civil: un enfoque desde la imputación objetiva”. En Domínguez Hidalgo, Carmen et al. (coordinadores): Estudios de Derecho Civil VIII. Santiago de Chile: Editorial LegalPublishing - Thomson Reuters, pp. 505-523. 
idea, privilegiando el criterio de la contribución causal del hecho ilícito y de la culpa de la víctima antes que comparar la magnitud de las faltas concurrentes involucradas ${ }^{127}$.

La solución sería diametralmente distinta si se basa en la gravedad del comportamiento: el autor del delito civil debe responder íntegramente de los perjuicios pues su hecho absorbe la imprudencia de la víctima y no procede la compensación de culpas. Es decir, "si alguna de las partes ha actuado con dolo se entiende normalmente excluida la responsabilidad compartida de la otra, aunque su negligencia tenga una incidencia causal relevante en el daño" 128 .

Esta aproximación coincide con la posición jurisprudencial inglesa y, en nuestra opinión, es un criterio sensato. En efecto, como se señaló en el acápite anterior, la influencia causal del hecho doloso es, por regla general, considerablemente superior a la relevancia causal de un hecho imprudente. De ahí que uno de nuestros más distinguidos civilistas, pese a favorecer la solución del dilema de la concurrencia de culpas mediante un criterio causal, admite que "La gravedad de la cual [de la culpa] es, generalmente, un índice de la eficacia causal: mientras mayor sea la posibilidad objetiva del daño, más grave es la culpa que lo provoca. En efecto, un hombre diligencia se habría abstenido en especial de ese acto, tanto más que la posibilidad de producción de dicho perjuicio era considerable. Así, la eficacia causal y la gravedad de la culpa son, con mucha frecuencia, coincidentes" 129 .

Es más, en el último tiempo se ha esgrimido persuasivamente que "en la medida que aceptemos que la causalidad normativa está (entre otros factores) determinada por el carácter culpable de la conducta, se entiende también por qué una conducta dolosa, tiene preferencia causal

127 "... la culpa de la víctima en el derecho chileno, como regla de atenuación de responsabilidad, tiene el efecto de reducir la obligación indemnizatoria del autor del daño, pues no resulta legitimo que este repare la totalidad del daño que la víctima contribuyó a crear... cuando la única causa del daño es el hecho del demandado, autor del perjuicio, no puede este pretender exonerarse parcialmente de su responsabilidad, aun cuando la víctima hubiere desplegado previamente una actividad o conducta infraccional... toda vez que corresponde atenerse a una relación de causalidad y no a un contexto de culpabilidad": Corte Suprema. 21 de septiembre de 2012. Rol $N^{\circ}$ 2.197-2010, cons. $4^{\circ}$ y $8^{\circ}$. "Correa con Fisco". En similar sentido: Corte Suprema. 25 de marzo de 2013. Rol N 2.695-2012. "Palominos con Municipalidad de Concón"; Corte Suprema. 11 de junio de 2013. Rol N 9.907-2011. "Zárate con Empresa de Ferrocarriles del Estado y Municipalidad de Chiguayante"; Corte Suprema. 29 de julio de 2013. Rol No 2.049-2013. "Montero con Servicio de Salud de Valparaíso-San Antonio"; Corte Suprema. 8 de agosto de 2013. Rol N³.656-2013. "Morales con Municipalidad de Viña del Mar".

128 Barros Bourie (2006) 438.

129 Domínguez Águila, Ramón (1966) "El hecho de la víctima como causal de exoneración de responsabilidad civil”. Revista de Derecho Universidad de Concepción, N 136, pp. 29-54, p. 46. 
por sobre una conducta "simplemente" culpable"130. En apoyo de la idea de que "la culpa no compensa el dolo" puede citarse una notable sentencia que declaró que "... el recurso pretende que la conducta de la víctima directa fue causa de su muerte o daño que repercutió en los demandantes de autos, pues si no hubiere participado en los aciagos hechos nada habría ocurrido. Sin embargo, la conducta dolosa de Ramirez Inostroza fue inesperada para la victima directa, la que pudo confiar en forma legitima que el funcionario policial se desempeñaría en forma correcta. De ahi que quepa concluir que el daño ocasionado por el victimario no pueda concurrir en términos de imputabilidad objetiva con la conducta de la victima directa, la que si bien fue necesaria para el acaecimiento de los hechos, no le resulta imputable en términos de causalidad normativa. Asi las cosas, mal podría pensarse que la víctima participó en términos causales e imputables en su propio daño, lo que conlleva la impertinencia del artículo 2330 del Código Civil'131.

Esta sentencia muestra cómo el problema de la concurrencia del delito civil perpetrado por el autor (que generalmente provendrá de un delito penal, como sucedió en el caso sobre el cual recayó este fallo) y la negligencia de la víctima - ambos concausas del daño sufrido por esta últimadebiera resolverse por la imputación de responsabilidad total del autor del hecho intencional atendida su mayor potencia causal que la imprudencia de la víctima.

\section{CONCLUSIONES}

1. El elemento intencional tiene relevancia en tres dimensiones dentro del derecho inglés de los ilícitos extracontractuales: es un presupuesto para atribuir la responsabilidad por actos de competencia desleal y ejercicio abusivo de acciones judiciales; es un factor causalmente importante que produce el agravamiento de la responsabilidad, extendiéndola a todos los daños que derivan directamente del ilícito intencional, incluso los perjuicios que no habrían podido preverse conforme al estándar de diligencia

130 San Martín Neira, Lilian (2015) "La culpa de la víctima en la estructura de la responsabilidad civil extracontractual”, pp. 1-16, p. 16. Ponencia inédita, presentada en las XIII Jornadas Nacionales de Derecho Civil, organizadas por el Departamento de Derecho Privado de la Facultad de Ciencias Jurídicas y Sociales de la Universidad de Concepción (octubre de 2015) y que -a la fecha del presente artículo- aún no es publicada en la colección Estudios de Derecho Civil XI. Agradezco a la profesora San Martin su gentileza en proporcionarme un ejemplar de su trabajo.

131 Corte Suprema. 15 de diciembre de 2015. Rol No 3.294-2015, cons 8. "Quezada y Otros con Fisco de Chile". Agradezco esta referencia jurisprudencial a la profesora Lilian San Martín. 
debida aplicable en la especie, y es un componente que absorbe la culpa concurrente de la víctima e impide que la responsabilidad del autor del delito quede sujeta a reducción.

2. El panorama en Chile es comparable únicamente en el primero de los sentidos referidos. En efecto, la jurisprudencia existente supedita la imputación de responsabilidad civil por actos de competencia desleal y ejercicio abusivo de acciones judiciales a la presencia de dolo. La mera negligencia no permite atribuir el deber de indemnizar en estos ámbitos. Esto en sí constituye una calificación acotada aunque significativa al estatuto general y común de la responsabilidad extracontractual. El hecho de restringir la responsabilidad civil a comportamientos dolosos -o que al menos revelen una indiferencia absoluta hacia los demás, actitud equiparable a la culpa grave-, es un criterio útil para que el juez sopese el derecho a la seguridad de la víctima con la libertad de competir o actuar en juicio del demandado, cuyo ejercicio inexorablemente afecta a terceros.

3. La jurisprudencia chilena no ha declarado que el delito da lugar a una indemnización de perjuicios más amplia que el cuasidelito civil, ni ha reconocido que el autor del dolo asume la responsabilidad íntegra a pesar de la culpa concurrente de la víctima. Sin embargo, el estudio del derecho anglosajón y su confrontación con nuestro ordenamiento sugiere que la repercusión del dolo sobre la causalidad es más -conceptual y probabilísticamente- intensa que la incidencia de la culpa en el nexo causal. Si esto es así, parece razonable considerar la posibilidad de extender la responsabilidad civil extracontractual por delitos a todos los daños causados directamente por aquellos, incluso los que un buen padre de familia no habría podido prever en las mismas circunstancias. En efecto, las consecuencias del hecho intencional nunca son demasiado lejanas y su autor mal puede pretender beneficiarse con la limitación de su responsabilidad a los perjuicios previsibles. La previsibilidad es una noción consustancial a la culpa y a la causalidad adecuada, donde el parámetro de los acontecimientos normales u ordinarios dice relación con lo que una persona prudente habría previsto. La previsibilidad es ajena al dolo o, si se prefiere, el propósito deliberado de dañar excede toda previsión.

4. La mayor incidencia causal del dolo en comparación a la de la culpa permite asimismo sugerir que en situaciones en que los dańos alegados provengan en parte del delito civil cometido por el demandado y en parte de la culpa (no grave) de la víctima, el peso de la responsabilidad debería ser soportado exclusivamente por el autor del ilícito intencional. 


\section{BIBLIOGRAFÍA CITADA}

Aedo Barrena, Cristian (2013) "El tratamiento dogmático de la culpa de la víctima en la responsabilidad civil: un enfoque desde la imputación objetiva”. En Domínguez Hidalgo, Carmen et al. (coordinadores): Estudios de Derecho Civil VIII. Santiago de Chile: Editorial LegalPublishing - Thomson Reuters, pp. 505-523.

Aedo Barrena, Cristian (2001) El daño moral en la responsabilidad contractual y extracontractual. Santiago de Chile: Editorial Libromar, 517 pp.

Alessandri Rodríguez, Arturo (1943) De la responsabilidad extracontractual en el derecho civil chileno. Santiago de Chile: Imprenta Universitaria, $644 \mathrm{pp}$.

Bahamondes Oyarzún, Claudia y Pizarro Wilson, Carlos (2012) "La exposición de la víctima al daño: desde la culpabilidad a la causalidad”. Revista de Derecho de la Pontificia Universidad Católica de Valparaiso, Vol. 39, pp. 39-52.

BANFI DEL Río, Cristián (2013) Responsabilidad civil por competencia desleal. Estudio de derecho chileno y comparado. Santiago de Chile: Editorial LegalPublishing - Thomson Reuters, 382 pp.

BANFi Del Río, Cristián (2012) "Por una reparación integral del daño extracontractual limitada a los hechos dolosos o gravemente negligentes". Revista Ius et Praxis, Año 18, N², pp. 3-32.

BARros Bourie, Enrique (2006) Tratado de responsabilidad extracontractual. Santiago: Editorial Jurídica de Chile, 1230 pp.

CAne, Peter (2001) "Responsibility and fault: a relational and functional approach to responsibility". En Cane, Peter \& Gardner, John: Relating to Responsibility. Essays for Tony Honoré on his Eightieth Birthday. Oxford: Hart, 246 pp.

Cane, Peter (1997) The anatomy of tort law. Oxford: Hart, 264 pp.

Chadwick Valdés, Tomás (1939) “De la naturaleza jurídica del dolo civil”. Revista de Derecho y Jurisprudencia, T. 36, I, pp. 5-105.

Corral Talciani, Hernán (2013) Lecciones de responsabilidad extracontractual. 2a Ed. Santiago de Chile: Editorial LegalPublishing Thomson Reuters, 475 pp.

Corral Talciani, Hernán (2010) Contratos y daños por incumplimiento. Santiago de Chile: Editorial Abeledo Perrot - LegalPublishing, 328 pp.

Deakin, Simon, Johnston, Angus \& Markesinis, Basil (2013) Markesinis and Deakin's tort law. $7^{\text {th }}$ Ed. Oxford: Clarendon Press, 907 pp. 
Díez Schwerter, José Luis (1997) El daño extracontractual. Jurisprudencia y doctrina. Santiago de Chile: Editorial Jurídica de Chile, 291 pp.

Domínguez Águila, Ramón (2010) "Los límites al principio de reparación integral". Revista Chilena de Derecho Privado, No 15, pp. 9-28.

Domínguez Águila, Ramón (2001) “Aspectos de la relación de causalidad en la responsabilidad civil con especial referencia al derecho chileno". Revista de Derecho Universidad de Concepción, No 209, pp. 7-27.

Domínguez Águila, Ramón (1990) "Consideraciones en torno a la noción de daño en la responsabilidad civil. Una visión comparatista”. Revista de Derecho Universidad de Concepción, N 188, pp. 125-168.

Domínguez Hidalgo, Carmen (2010) "El principio de reparación integral del daño y su contenido: algunas consecuencias para el derecho chileno". En Departamento de Derecho Privado Universidad de Concepción (coordinador): Estudios de Derecho Civil $V$. Santiago de Chile: Editorial Abeledo Perrot - LegalPublishing, pp. 671-685.

Domínguez Hidalgo, Carmen (2006) "Algunas consideraciones en torno a la función de la responsabilidad civil en Chile". En Varas Braun, Juan Andrés y Turner Saelzer, Susan (coordinadores): Estudios de Derecho Civil. Santiago de Chile: Editorial LexisNexis, pp. 585605.

Hart, Herbert L.A. \& Honoré, Tony (2002) Causation in the Law. $2^{\text {nd }}$ Ed. Oxford: Oxford University Press, 516 pp.

Honoré, Tony (1995) “The morality of tort Law". En Owen, David (editor): Philosophical foundations of tort law. Oxford: Clarendon Press, 510 pp., pp. 72-95.

Jones, Michael (2014) Clerk \& Lindsell on torts. $21^{\text {st }}$ Ed. London: Sweet \& Maxwell - Thomson Reuters, 2374 pp.

Kenny, Anthony (1966) "Intention and purpose". Journal of Philosophy, No 63, pp. 642-651.

Landes, William \& Posner, Richard (1987) The economic structure of tort law. Cambridge, MA: Harvard University Press, 329 pp.

Larraín PÁez, Cristián (2009) "Aproximación a los punitive damages". En Pizarro Wilson, Carlos (coordinador): Estudios de Derecho Civil $I V$. Santiago de Chile: Editorial LegalPublishing, pp. 707-719.

McGregor, Harvey (2014) McGregor on damages. 19 $9^{\text {th }}$ Ed. London: Sweet \& Maxwell - Thomson Reuters, 2146 pp.

Peña López, Fernando (2011) Dogma y realidad del derecho de daños: imputación objetiva, causalidad y culpa en el sistema español y en los PETL. Cizur Menor: Editorial Thomson Reuters, 159 pp. 
Reglero Campos, Fernando (2014) "Los sistemas de responsabilidad civil”. En Reglero Campos, Fernando y Busto Lago, José Manuel (coordinadores): Tratado de responsabilidad civil. 5a edición. Cizur Menor: Editorial Thomson Reuters, T. I, 1896 pp., cap. 2, pp. 265315.

Rogers, W.V. Horton (2010) Winfield and Jolowicz on tort. $18^{\text {th }}$ Ed. London: Sweet \& Maxwell, 1225 pp.

Rudden, Bernard (1991) “Torticles". Tulane Civil Law Forum, Vol. 6, pp. 105-129.

SAN Martín Neira, Lilian (2015) "La culpa de la víctima en la estructura de la responsabilidad civil extracontractual”, pp. 1-16. Ponencia inédita presentada en las XIII Jornadas Nacionales de Derecho Civil, organizadas por el Departamento de Derecho Privado de la Facultad de Ciencias Jurídicas y Sociales de la Universidad de Concepción (octubre de 2015).

Segura Riveiro, Francisco (2005) "Algunas consideraciones sobre la pena privada y los dańos punitivos en el derecho civil chileno”. En Varas Braun, Juan Andrés y Turner Saelzer, Susan (coordinadores): Estudios de Derecho Civil. Santiago de Chile: Editorial LexisNexis, pp. 635-655.

TAPiA SuÁrez, Orlando (2007) De la responsabilidad civil en general y de la responsabilidad delictual entre los contratantes. $3^{\text {a }}$ Ed. Santiago de Chile: Editorial LexisNexis, 654 pp.

WeIr, Tony (2006) An introduction to tort law. $2^{\text {nd }}$ Ed. Oxford: Oxford University Press, 270 pp., p. 16.

Wright, Richard (1985) "Causation in tort law". California Law Review, Vol. 73, pp. 1737-1828.

\section{JURISPRUDENCIA CITADA}

\section{JURISPRUDENCIA NACIONAL}

Corte Suprema. 15 de noviembre de 1927. "Wessel Duval y Cía. con Errázuriz”. RDJ, T. 25 , sec. $1^{\text {a }}$, p. 501.

Corte Suprema. 14 de abril de 1928. "Madariaga con Ferrocarriles del Estado”. RDJ, T. 26, sec. $1^{\mathrm{a}}$, p. 141.

Corte Suprema. 26 de agosto de 1941. "Porzio con Shell Mex Chile Ltda”. RDJ, T. 39, sec. $1^{\text {a }}$, p. 203.

Corte Suprema. 24 de septiembre de 1943. "Jaramillo con Alfonso y Otros”. RDJ, T. 41, sec. $1^{\text {a }}$, p. 228.

Corte Suprema. 23 de septiembre de 1947. "Perkes y Otra con Garibaldi”. RDJ, T. 45, sec. $1^{\text {a }}$, p. 216. 
Corte Suprema. 14 de abril de 1953. "Fueyo y Otros con Urbistondo". $R D J$, t. 50 , sec. $4^{\text {a }}$, p. 40.

Corte Suprema. 12 de agosto de 1953. "Silva con Arce". RDJ, T. 50, sec. $1^{\text {a }}$, p. 288.

Corte de Apelaciones de Santiago. 3 de octubre de 1958. Corte Suprema. 12 de mayo de 1959. "Friedl con Empresa de Transportes Colectivos del Estado". RDJ, T. 56, sec. 1a, p. 133.

Corte Suprema. 15 de septiembre de 1964. "Contra Maguire Seguel, John”. RDJ, T. 61, sec. 4a, p. 372.

Corte Suprema. 24 de marzo de 1965. "Contra Asjra Bondo, Alberto". $R D J$, T. 62 , sec. $4^{\mathrm{a}}$, p. 31.

Corte Suprema. 16 de octubre de 1970. "Contra Lama, Abraham". RDJ, T. 67 , sec. $4^{\mathrm{a}}$, p. 424.

Corte Suprema. 26 de noviembre de 1970. "Agostinelli con Fisco". RDJ, T. 67 , sec. $1^{\text {a }}$, p. 535.

Corte Suprema. 8 de noviembre de 1971. "Contra Álvarez Hormazábal, Domingo y Álvarez, Domingo”. RDJ, T. 68, sec. 4a , p. 274.

Corte Suprema. 17 de octubre de 1972. "Contra Rivas Moreno, Jorge". $R D J$, T. 69, sec. $4^{\text {a }}$, p. 168.

Corte Suprema. 6 de noviembre de 1972. "Contra Vergara Pérez, Eugenio". RDJ, T. 69, sec. $4^{\text {a }}$, p. 181.

Corte Suprema. 12 de agosto de 1981. "Contra Martínez González, Miguel”. RDJ, T. 78, sec. 4a , p. 120.

Corte Suprema. "Contra Oyanedel Severino, Alfonso y Otro". 27 de octubre de 1983. RDJ, T. 80, sec. $4^{\mathrm{a}}$, p. 121.

Corte Suprema. 19 de abril de 1984. "Contra Celedón Silva, Jaime". $R D J$, T. 81 , sec. $4^{\text {a }}$, p. 29.

Corte de Apelaciones de Rancagua. 18 de marzo de 1986. "Contra Báez, Juan”. RDJ, T. 83, sec. 4a, p. 36.

Corte Suprema. 14 de septiembre de 1987. "Contra Gallardo Díaz, Manuel". RDJ, T. 84, sec. 4a , p. 137.

Corte de Apelaciones de Santiago. 26 de septiembre de 1990. "Curaqueo y Otros con Congregación del Santísimo Redentor". GJ, $\mathrm{N}^{\circ} 123$, p. 47.

Corte de Apelaciones de Santiago. "Contra Montalva Navarro, Reinaldo". 4 de septiembre de 1991. RDJ, T. 88, sec. 4a, p. 138.

Corte de Apelaciones de Santiago. 27 de diciembre de 1996. "Miranda y Otra con Banco de Santiago". GJ, N 198, p. 55.

Corte de Apelaciones de Talca. 29 de agosto de 1997. Corte Suprema. 4 de noviembre de 1997. "Contra Escobar Vera, Manuel". $R D J$, T. 94, sec. $4^{\mathrm{a}}$, p. 258.

Corte Suprema. 2 de diciembre de 1998. "Contra Berenguela Orellana, Javier”. $F M, \mathrm{~N}^{\circ} 481$, p. 2737. 
Corte Suprema. 19 de mayo de 1999. "Contra Monroy Izquierdo, Mario”. FM, N $\mathrm{N}^{\circ} 486$, p. 730.

Corte Suprema. 24 de enero de 2002. "Oviedo y Otros con Servicio de Salud de Talcahuano”. GJ, N²59, p. 38.

Corte de Apelaciones de Santiago. 1 de septiembre de 2003. "Soto con Banco Santander”. GJ, N $\mathrm{N}^{\circ} 279$, p. 115.

Corte Suprema. 24 de marzo de 2004. "Perrot con Banco del Estado de Chile”. GJ, No 285, p. 138.

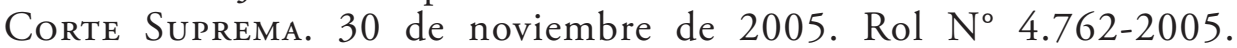
"Asociación Gremial de Industrias Proveedoras, Agip A.G”.

Corte Suprema. 7 de agosto de 2008. Rol No 935-2008. "Contra Fuenzalida Durán, Felipe”.

Corte de Apelaciones de Santiago. 1 de septiembre de 2009. Rol No 4.318-2008. "Silva con Soc. Sade Chile Ltda".

Corte de Apelaciones de Santiago. 2 de septiembre de 2010. Rol N ${ }^{\circ}$ 3.377-2008. "Sociedad Nacional de Procesamiento de Datos S.A. con Sone Cisternas y Transporte Inteligente Multimodal Chile S.A".

2o Juzgado Civil de Santiago. 30 de enero de 2009. Rol N 12.2162007. Corte de Apelaciones de Santiago. 22 de enero de 2010. Rol N ${ }^{\circ}$ 1.414-2009. Corte Suprema. 12 de noviembre de 2010. Rol N 3.655-2010. "Compañía de Petróleos de Chile Copec S.A. con Capdevilla Transportes Limitada”.

200 Juzgado Civil de Santiago. 27 de noviembre de 2008. Rol N 11.535-2008. Corte de Apelaciones de Santiago. 13 de enero de 2010. Rol No 868-2009. Corte Suprema. 17 de agosto de 2012. Rol N ${ }^{\circ}$ 2.428-2010. "Sociedad Imperial Travel \& Reps. Ltda. con Sociedad Imperial Tours Ltda”

Corte Suprema. 21 de septiembre de 2012. Rol No 2.197-2010. "Correa con Fisco".

Corte Suprema. 15 de enero de 2013. Rol N 9.336-2010. "Industrias Princesa Limitada con Fisco de Chile".

Corte Suprema. 25 de marzo de 2013. Rol N 2.695-2012. "Palominos con Municipalidad de Concón”.

Corte Suprema. 11 de junio de 2013. Rol N 9.907-2011. "Zárate con Empresa de Ferrocarriles del Estado y Municipalidad de Chiguayante".

Corte Suprema. 23 de julio de 2013. Rol No 8.243-2012. "Laboratorios Recalcine S.A. con Roche Chile Ltda”.

Corte Suprema. 29 de julio de 2013. Rol No 2.049-2013. "Montero con Servicio de Salud de Valparaíso-San Antonio".

Corte Suprema. 8 de agosto de 2013. Rol N³.656-2013. "Morales con Municipalidad de Viña del Mar”.

$8^{\circ}$ Juzgado Civil de Santiago. 12 de julio de 2012. Rol N 15.1392011. Corte de Apelaciones de Santiago. 1 de abril de 2014. 
Rol No 6.335-2012. Corte Suprema. 31 de julio de 2014. Rol N ${ }^{\circ}$ 11.531-2014. "Prolam con Sánchez".

$22^{\circ}$ Juzgado Civil de Santiago. 9 de julio de 2014. Rol No 21.9502012. "WAC Research S.A. con Octogone Chile S.A y Octogone Gestión S.A".

Corte de Apelaciones de Concepción. 16 de abril de 2015. Rol No 547-2014. "Maquival Chile Limitada con Eserma S.A"

120 Juzgado Civil de Santiago. 26 de mayo de 2015, Rol No 5.0962012. "Danone con Soprole".

Corte Suprema. 12 de junio de 2015. "Holzmann con Agrícola Las Colinas de Tapihue Limitada”. Rol N²6.201-2014.

Corte Suprema. 3 de diciembre de 2015. Rol N ${ }^{\circ}$ 29.365-2014. "Vásquez y Otros con Hospital Carlos van Buren".

Corte Suprema. 15 de diciembre de 2015. Rol No 3.294-2015. "Quezada y Otros con Fisco de Chile".

\section{JURISPRUDENCIA INGLESA}

Allan v. New Mount Sinai Hospital (1980) 109 D.L.R. (3d) 634.

Allen v. Flood [1898] A.C. 1.

Alliance and Leicester Building Society v. Edgestop Ltd [1993] 1 W.L.R. 1462.

Archer v. Brown [1985] Q.B. 401.

Banks v. Cox [2002] EWHC 2166.

Banque Bruxelles Lambert SA v. Eagle Star Insurance Co Ltd [1997] A.C. 191.

Barings Plc (In Liquidation) v. Coopers \& Lybrand (A Firm) [2002] EWHC 461.

Barton v. County NatWest Ltd. [1999] Lloyd's rep. Banking 408.

Bourgoin SA v. Ministry of Agriculture [1986] Q.B. 716.

Bradford v. Pickles [1895] A.C. 587.

Butler-Creagh v. Hersham [2011] EWHC 2525.

Caparo Industries Plc. v. Dickman [1990] 2 A.C. 605.

Christie v. Davey [1893] 1 Ch. 316.

Churchill v. Siggers (1854) 118 E.R. 1389.

Clark v. Urquhart [1930] A.C. 28.

Clarke v. Postan (1834) 172 E.R. 130.

Clifford v. Chief Constable of Hertfordshire [2011] EWHC 815.

Corporación Nacional del Cobre de Chile v. Sogemin Metal Ltd [1997] 1 W.L.R. 1396.

Crawford Adjusters (Cayman) Ltd. v. Sagicor General Insurance (Cayman) Ltd. [2014] A.C. 366. 
Crofter Handwoven Harris Tweed Co Ltd v. Veitch [1942] A.C. 435.

Derry v. Peek (1889) LR 14 App.Cas. 337.

Donoghue v. Stevenson [1932] A.C. 562.

Downs v. Chappell [1997] 1 W.L.R. 426.

Doyle v. Olby (Ironmongers) Ltd. [1969] 2 Q.B. 158.

Environment Agency v. Empress Car Co (Abertillery) Ltd [1999] 2 A.C. 22.

Gibbs v. Rea [1998] A.C. 786.

Gilding v. Eyre (1861) 142 E.R. 769.

Grainger v. Hill (1838) 132 E.R. 769.

Gregory v. Portsmouth City Council [2000] 1 A.C. 419.

Hedley Byrne \& Co. Ltd. v. Heller \& Partners Ltd. [1964] A.C. 465.

HIH Casualty and General Insurance Ltd. v. Chase Manhattan Bank Ltd. [2001] 2 Lloyd's Rep. 483.

KBC Bank v. Industrial Steels (UK) Ltd [2001] 1 Lloyd's Rep. 370.

Kinch v. Rosling [2009] EWHC 286.

Knightley v. Johns [1982] 1 W.L.R. 349.

Kuddus v. Chief Constable of Leicestershire Constabulary [2002] 2 A.C. 122.

Langridge v. Levy (1873) 2 M. \& W. 519.

Letang v. Cooper [1965] 1 Q.B. 232.

Liesbosch Dredger v. S.S. Edison [1933] A.C. 449.

Lonrho Ltd v. Shell Petroleum Co Ltd (No.2) [1982] A.C. 173.

Lonrho Plc v. Al-Fayed (No.1) [1992] 1 A.C. 448.

Lumley v. Gye (1853) 118 E.R. 749.

Mullet v. Mason (1866) L.R. 1 C. \& P. 559.

Nationwide Building Society v. Dunlop Haywards (DHL) Ltd [2009] EWHC 254.

Nationwide Building Society v. Thimbleby \& Co [1999] P.N.L.R. 733.

$O B G$ v. Allan, Douglas v. Hello! \& Mainstream v. Young [2008] 1 A.C. 1.

Pan Atlantic Insurance Co Ltd v. Pine Top Insurance Co Ltd [1995] 1 A.C. 501.

Parabola Investments Ltd. v. Browalia Cal Ltd. [2011] Q.B. 477.

Pasley v. Freeman (1789) 3 TR 51.

Perrettv. Collins [1998] 2 Lloyd's Rep. 255.

Quinn v. Leathem [1901] A.C. 495.

$R$. v Caldwell [1982] A.C. 341.

Rahman v. Arearose Ltd [2001] Q.B. 351.

Ratcliffe v. Evans [1892] 2 Q.B. 524.

Reddaway v. Banham [1896] A.C. 199.

Revenue and Customs Commissioners con Total Network SL [2008] 1 A.C. 1174.

Rookes v. Barnard [1964] A.C. 1129.

Scott v. Shepherd (1773) 2 W.Bl. 892. 
Shelley v. Paddock [1980] Q.B. 348.

Slough Estates Ltd v. Welwyn-Hatfield DC [1996] 2 P.L.R. 50.

Smith New Court Securities Ltd. v. Scrimgeour (Asset Management) Ltd. Vickers [1997] A.C. 254.

Sorrell v. Smith [1925] A.C. 700.

St Paul Travelers Insurance Co Ltd. v. Okporuah [2006] EWHC 2107.

Standard Chartered Bank v. Pakistan National Shipping Corporation [2002] 3 W.L.R. 1547.

Stapley v. Gypsum Mines Ltd [1953] A.C. 663.

Stevens v. Midland Counties Ry (1854) 10 Ex. 352.

Swindle v. Harrison [1997] 4 ALL E.R. 705.

Tempest v. Snowden [1952] 1 K.B. 130.

The Wagon Mound (No. 1) [1961] A.C. 388.

Thompstone v. Tameside and Glossop Acute Services NHS Trust [2008] EWCA Civ. 5.

Three Rivers DC v. Bank of England (No.3) [2003] 2 A.C. 1.

Wainwright v. Home Office [2001] EWCA Civ. 2081, [2004] 2 A.C. 406. Weld-Blundell v. Stephens [1920] A.C. 956.

Wilkinson v. Downton [1897] 2 Q.B. 57

Wilson v. Pringle [1987] Q.B. 237. 